\title{
IMPACTS OF SUBWAY PRICING ON FARE EQUALITY AMONG PASSENGERS: A TORONTO CASE STUDY
}

\author{
by \\ Michael Lok Kan Chung, \\ BES, University of Waterloo, 2012 \\ A Major Research Paper \\ presented to Ryerson University \\ In partial fulfillment of the requirements for the degree of \\ Master of Planning \\ in \\ Urban Development
}

Toronto, Ontario, Canada, 2014

(C) Michael Lok Kan Chung 2014 


\section{Author's Declaration}

I hereby declare that I am the sole author of this major research paper. This is a true copy of the major research paper, including any required final revisions, as accepted by my examiners.

I authorize Ryerson University to lend this major research paper to other institutions or individuals for the purpose of scholarly research

I further authorize Ryerson University to reproduce this major research paper by photocopying or by other means, in total or in part, at the request of other institutions or individuals for the purpose of scholarly research.

I understand that my major research paper may be made electronically available to the public. 


\title{
IMPACTS OF SUBWAY PRICING ON FARE EQUALITY AMONG PASSENGERS: A TORONTO CASE STUDY
}

\author{
Michael Lok Kan Chung, 2014 \\ Master of Planning \\ in \\ Urban Development \\ Ryerson University
}

\begin{abstract}
This project examines fare equity amongst socio-demographic groups of passengers who use Toronto Transit Commission's subway system. Existing literature theorizes and demonstrates that flat fare pricing strategies are inequitable between transit users. Disadvantaged groups, who often travel on off-peak hours and on short trips, typically subsidize transit users who travel on peak hours and long trips. Surveys were used to collect socio-demographic and trip characteristic data from $n=93$ subway passengers. Correlation was drawn between various socio-demographic variables and transit fare per kilometer travelled (which represented length of trips) and time of day in which the trips were taken. Using linear and binomial logistic regression modeling, the study found that subsidization were indeed occurring between passengers, but socio-demographic variables played no role with distance travelled or time of usage. The study concludes that the flat fare pricing policy employed by the TTC is likely equitable across socio-demographic groups of passengers, but it appears that a differentiated fare policy (instead of the current flat fare policy) might improve fairness between passengers.
\end{abstract}

Key words: transit fares, equity, subsidies, social exclusion 


\section{Acknowledgements}

I would like to thank my supervisor, Doctor Raktim Mitra for his continual guidance, advice, and instruction throughout the process of completing this MRP. Without Doctor Mitra's supervision, this research would not been possible. I would also like to thank David Cooper for generously offering his valuable feedback and accommodating me in ways that others would not.

I'm grateful for the support, in one way or another, I have received from my friends, family and colleagues. Special mention goes out to Zoe Kim, for being a phenomenal, helpful, and supportive friend, not only throughout the planning, research, and write up of this MRP, but also in life.

Finally, I would like to dedicate this paper to my parents, Deborah and Danny, who have been the absolute most amazing parents that a son can ask for. 


\section{Table of Contents}

1.0 Introduction $\quad 1-4$

2.0 Literature Review

2.1 Social Exclusion $\quad$ 5-7

2.2 Transportation and Mobility Barriers as a Case of Social Exclusion 7-9

2.3 Cost as a Barrier to Transportation and Mobility $10-12$

2.4 Transit Fares: Flat and Differentiated Pricing $\quad 12-14$

2.5 Flat Fares and Equability $14-17$

2.6 Purpose of MRP 17

$\begin{array}{lr}3.0 \text { Methodology } & 18-25\end{array}$

3.1 Data Collection $\quad 19-20$

3.2 Data Analysis $\quad 20-25$

4.0 Results $\quad$ 27-41

4.1 Survey Analysis $\quad$ 29-39

4.1.1 Distance Travelled and Fare Paid 31-33

4.1.2: Socio-demographic Variations in Subway System Users 34-37

4.2 Statistical Analysis 38-41

5.0 Discussion $\quad$ 42-51

5.1 Interpreting the results $\quad 42-47$

5.2 Implications for policy and practice $\quad 48-49$

5.3 Study Limitations $\quad 49-51$

6.0 Conclusions $\quad 52-53$

Appendix A $\quad$ 54-55

References $\quad$ 56-60 


\section{List of Tables}

4.1 Summary of socio-demographic and travel characteristics data 26

4.2 Results of Bivariate Linear Regression Analysis 38-39

4.3 Results of Multivariate Linear Regression analysis $\quad 39-40$

4.4 Results of Bivariate Logistic Regression Analysis $\quad$ 40-41

4.5 Results of Multivariate Logistic Regression Analysis $\quad 41-42$

5.1 Interpretation of linear regression results (Correlation between demographic $\quad 42-43$ variables and RPKM)

5.2 Interpretation of linear regression results (Correlation between demographic 43 variables and time of use) 


\section{List of Figures}

4.1 Breakdown of the locations and time periods at which surveys were collected 28

4.2 Purpose of trip

4.3 Trip origin and destination city

4.4 Distance travelled on the subway system

4.5 Fare paid per kilometer travelled (RPKM)

4.6 Rates paid per kilometer travelled (RPKM), separated by time of usage

4.7 Amount of money spent on transit each month

4.8 Age of subway users

4.9 Gender of subway users

4.10 Employment status of subway users

4.11 Household income of subway users

4.12 The number of years subway users have lived in Canada 


\subsection{Introduction}

Social exclusion is the phenomenon that prevents certain groups within a population from fully participating in society (Mathieson, et al 2008; Stanley, 2011). Those who are socially excluded are often limited in their access to important services and opportunities, such as employment, education, social services, and housing. This leads to further social exclusion as well as other serious problems such as poverty (Banister and Hall 1981; Bradshaw et al., 2004; Currie \& Delbosc, 2011; Giluliano, 2005), which can be caused by a number of factors including unemployment, poor housing, and bad health (Social Exclusion Unit, 1997). Literature has also identified transportation as a contributing factor to social exclusion. Barriers to accessible modes of transportation limit some individuals or groups of individuals from accessing important services and opportunities (Currrie \& Delbosc, 2011; Lucas, 2004). The same individuals who face transportation and mobility barriers are also the ones who depend on transit for day-today travel. For these people, the greatest limiting factor for transportation is often affordable fares.

Transit fares can be divided into two categories: flat fares and differentiated fares. Flat fares charge users the same price regardless of the time or distance the user travels within the system. A majority of transit systems in North America use a flat fare pricing strategy. New York City's Metropolitan Transportation Authority (MTA) for example, charges a flat rate of $\$ 2.50$ for use of the entire subway system at any time of the day (Metropolitan Transportation Authority). Differentiated fares on the other hand, are fares that charge users based on the time of usage, distance travelled, or a combination of both. This fare type can be time-based, zone-based, or distance-based (Cevero, 1990; 
Transportation Research Board, 2003). King County Metro, the transit operator for the Seattle Metropolitan Area, uses a time-based pricing strategy based on off-peak and peak hours (King County Metro, 2011). Vancouver's transit operator TransLink charges fares based on three zones of service (TransLink), while San Francisco's transit operator Bay Area Rapid Transit price fares based on distance travelled (Bay Area Rapid Transit).

Yet, literature has long theorized that flat fare pricing strategies are neither efficient nor equitable (Vickrey 1973; Altshuler, 1979). Flat fare pricing strategies often ignore the fact that the cost of operating transit systems are higher during peak periods and for longer routes. The additional costs stem from the need for increased usage of resources, such as employees to operate systems and fuel for transit vehicles to service peak demands and routes with longer distances (Cevero, 1981). Passengers who travel during off-peak periods and/or short trips therefore pay relatively more in relation to the operating cost for transit service than passengers who travel during peak periods and/or long trips. Theoretically, those who travel during off-peak periods and/or for short trips are often subsidizing those who travel during peak periods and/or long trips for their use of transit system.

Studies have shown that disadvantaged groups such as low income households, women, and recent immigrants travel more often during off-peak hours (Cevero, 1981; Pucher \& Renne, 2003). This is likely because they are predisposed to be employed parttime and/or within the service sector, and have training and services that require them to travel throughout the span of a day (Walker, 2014). They are also more likely to travel short trips (Axisa et al., 2011; Cevero, 1981; Pucher \& Renne, 2003), as disadvantage 
groups, especially low-income households, are concentrated in central cities where things are closer together and do not require long trips (Pucher \& Renne, 2003).

The two theories point to the conclusion that under a flat fare pricing strategy, those who are vulnerable to social exclusion, especially disadvantage groups, are subsidizing other passengers' use of transit services, resulting in an inefficient and inequitable situation.

Indeed, previous studies have demonstrated that flat transit fares are not equitable across socio-demographic groups. Rock (1975) found that distance related price inequities in Chicago's transit system caused a redistribution of income from blacks to whites. Similarly, Cevero (1981) found that flat fare pricing structures in three California transit agencies had modest inequities when compared to differentiated pricing systems. Finally, Luhrsen \& Taylor (1997) found that the flat fare pricing strategy used by Los Angeles' transit system disfavoured riders who wore more likely poor, non-white, young or old, and female as these groups make short and non-work trips more than comparable passenger groups.

All of the studies listed above focused on transit systems located in the United States. Transit fare equity in Canada remains understudied. The aim of this Major Research Project (MRP) is to bridge the gap in literature by analyzing the topic of fare equity amongst socio-demographic groups of passengers for Toronto's subway system. Like many other transit systems in North America, the Toronto Transit Commission (TTC) uses a flat fare pricing strategy for their subway, streetcar, and bus systems. The goal of this study is to explore whether the pricing strategy creates inequity between one or more 
groups of passengers over others and if so, which group or groups benefit under such fare pricing policies.

The study explores two research questions: (1) does a relationship exist between distance - expressed as rate per kilometer travelled (RPKM) - and a transit user's socio-demographic characteristics? And (2) does a relationship exist between the time of day that a trip takes place (i.e. off-peak hours or peak hours) and a transit user's sociodemographic characteristics?

The conclusions established in this study contribute to knowledge and practice in a number of ways. To the author's knowledge, this study is the first of its kind in Canada. The results of the study add to the existing literature on examining transit fare inequity, and more specifically, on determining whether flat fare pricing strategies are inequitable amongst passengers with different socio-demographic backgrounds. In practice, the study can better inform policy makers on the kind of action needed to resolve transportation/transit related social exclusion and poverty. The results of this study will be particularly useful to the TTC in determining whether the current fare pricing strategy is adequate, and if not, which fare pricing strategy would be the most efficientt and equitable for the system its passengers (especially disadvantaged groups). To other transit operators/transportation planners, the methodology used in this study could be modified and improved upon such that it is applicable to the local transit system in determining the most efficient and most equitable fare pricing strategy to adopt. 


\subsection{Literature Review}

This section provides a theoretical basis and justification for the proposed research. There exist a number of papers discussing transit fare inequity. A number of published case studies reached the conclusion that flat fare pricing strategies lead disadvantaged groups to provide subsidises for other passengers, creating an inequitable situation. Most of these studies focused on transit systems in the United Stations however. Similar studies on Canadian transit systems could not be identified. This gap is where the proposed research will fit into the existing body of knowledge.

The concept of social exclusion is introduced first as a framework for the study. Next, transportation and mobility barriers are discussed as a cause behind social exclusion. Economics as a contributing factor to transportation and mobility barriers are then examined, identifying transit fares as a limiting factor to accessibility to those who are dependent on transit for travel. The major theories and case studies behind the inequitabilities of flat fare pricing are also discussed. Finally, an extended justification for the study and the purpose of the project are outlined.

\subsection{Social exclusion}

Social exclusion describes a state in which a group or groups of people are being subjected to circumstances that restrict them from participating in certain aspects of society, such as employment, political activity, and social support (CEC 1993; Mathieson et al., 2008; Room, 1992; Silver, 1995; Stanley, 2011). The concept of social exclusion has been a topic of study in academia since the 1960s. One of the most notable early 
research on the topic was by Kain in 1968 studying the effects of racial segregation in the housing market on employment in black population. Politician Rene Lenoir brought the concept to policy in France during the 1970s when he used the term "les exclus" to describe people who are denied their rights to social citizenship due to their inability to maintain a stable income. Over the next decades, the idea of social exclusion spread rapidly throughout the European Union, attaching itself to discussion of anti-poverty policies and programs (Mathieson et al., 2008). The United Kingdom recognized the concept in 1997 when a newly elected Labour government established the Social Exclusion Unit to facilitate research and policy around the issue (Currie \& Delbosc, 2011; Mathieson et al., 2008; Stanley, 2011). By 2005, social exclusion became common public discourse and was imbedded in numerous government policies (Levitas, 2005). Despite its popularity in Europe, the language of social exclusion has largely been absent in North America (Bradshaw et al., 2004).

The concept exists in the United States, but only under the term "underclass" and has a focus on African-American population. Canada has been slow to integrate the concept into policy and action. There has been little interest from the federal government in tackling the issue (Mackinnon, 2008). Yet, recent developments on the provincial level may indicate that social inclusion is an increasingly relevant topic in social policies. Quebec, for example, was the first province to take notice of the issue, enacting Act to Combat Poverty and Social Exclusion, a comprehensive strategy to combat poverty and social exclusion in 2004. Since then, Quebec's government have invested over $\$ 3$ billion in the strategy and its initiatives. Manitoba and Prince Edward Island mirrored Quebec's action and developed the Poverty Strategy Act in 2011 and the Social Action Plan in 2012, 
respectively. The aim of these policies were to eliminate poverty and foster social inclusion (Seguin).

Exclusion is often the result of unequal power dynamics in economic, societal, political, and cultural dimensions between individuals, communities, institutions, nations and regions (Department for Internal Development, 2005; Lin et al., 2012; Mathieson et al., 2008). Factors underlying social exclusion are rarely mutual exclusive (Governance and Social Development Resource Centre), however causes can be identified individually. For example, unemployment, low income, poor housing, high crime, bad health, education, low literacy rates, language barriers, and lack of access to public services are all cited causes to social exclusion (Bradshaw et al., 2004; Bucciarelli et al., 2012; Lin et al., 2012; Social Exclusion Unit, 1997)

\subsection{Transportation and Mobility Barriers as a Cause of Social Exclusion}

Recent literature also point to transportation and mobility barriers as a contributing factor to social exclusion (Bradshaw et al., 2004). Although inequality in transportation and mobility has been documented as early as 1973 by Wachs and Humagai in the US and 1981 by Banister and Hall in the UK (Lucas, 2012), the topic was largely overlooked in the social exclusion discussion. In 2000, some discussion began with Church, Frost, \& Sullivan's (2000) study on transportation exclusion in London, but it was not until the Social Exclusion Unit's seminal report Making the Connections: Final Report on Transport and Social Exclusion published in 2003 that transportation and mobility barriers became a prominent topic in social exclusion dialogue. This seminal report found people who experienced transportation problems were also those who were traditionally defined as 
having the greatest vulnerability to social exclusion (Stanley, 2011). Subsequently, there was a considerable increase in academic interest on the topic and in policy development that connected social exclusion to transport planning in the UK, Commonwealth countries, and mainland Europe (Lucas, 2012).

Transportation clearly plays an important role in society. Groups that are experiencing transportation and mobility barriers such as the inability to afford transit fares and/or physical barriers to operating a vehicle/accessing public transit are limited in their access to important services and opportunities including employment, education, services, and housing, and thus subjected to social exclusion (Banister and Hall 1981; Bradshaw et al., 2004; Currie \& Delbosc, 2011; Giluliano, 2005;). There are several drivers to transportation related social exclusion. Literature utilized a number of ways to define these drivers. Church et al. (2000) in an early report on social exclusion and transportation, for example, identified seven "mobility limitations" in which a transportation system contributed to exclusion: (1) Physical exclusion relating to the physical barriers of the transport system and the built environment that prevents or limits usage from certain groups of people; (2) Geographical exclusion relating to poor transport provision for peripheral and rural homes; (3) Exclusion from facilities relating to the lack of access to key services due to dispersed land use patterns; (4) Economic exclusion relating to the cost of travel limiting one's access to employment, which may impact their income; (5) Time-based exclusion relating to other commitments that may constraint an individual's available time for travel; (6) Fear-based exclusion relating to perceptions of safety affects how transport facilities are used; and (7) Space exclusion relating to security and space 
management strategies of places that could encourage or discourage usage of transportrelated spaces

Wixey et al. (2005) used seven categories similar in content to Church et al. (2000), but expanded to classify the relation between transport and social exclusion: (1) Spatial, describing the unreasonably long distance and time that one have to travel to access their destination; (2) Temporal, describing the certain destinations are not accessible on certain times or dates due to service hours; (3) Personal, describing the characteristics of user that prevents them from using a transport system (e.g. physical, mental etc.); (4) Financial, relating to the high cost of travelling; (5) Environmental, describing users or other groups affected by negative externalities of a transport system; (6) Infrastructural, describing transport infrastructure acting as a physical barrier to communities; and (7) Institutional, describing the policies or rules that exclude usage from certain groups (Currie \& Delbosc, 2011)

Lucas (2004b) used a different approach all together and proposed three broad, interconnected groupings that ties transport to social exclusion: (1) Activities, which includes settlement types, topography, environmental aspects, level of condition of supporting infrastructure, and level and quality of local services; (2) People, which includes age, gender, skills and ability, ethnicity/race, dependants, responsibilities, and available resources; and (3) Transport, type, availability, suitability, cost of travel, information, and staffing. Other literature (e.g. Bradshaw, 2004; Currie \& Delbosc, 2011; Social Exclusion Unit, 2003) used one or more categories listed above to link transportation and mobility to social exclusion. 


\subsection{Cost as a Barrier to Transportation and Mobility}

A factor that was almost universally mentioned by literature as a transportation and mobility related cause of social exclusion was the economics of transportation. Church et al. (2000), Wixey et al. (2005), and Lucas (2004b) all cited the high cost of travel as contributor to exclusion. Indeed, Social Exclusion Unit's (2003) seminal publication on transport and social exclusion in the United Kingdom listed cost of transport as one of the five key barriers to accessing services and recommended that travel should be made more affordable to increase accessibility (Social Exclusion Unit, 2003). A similar claim was made by the Australian Department of Primate Minister and Cabinet, citing the differences in cost and ability to pay for transport services as one of the factor associated with transport disadvantaged (Morgan, 1992). Overall, the consensus is that high transportation costs limit mobility, impacting accessibility to services and opportunities, resulting in social exclusion.

Cost of travel is often a major barrier for those most vulnerable to social exclusion, especially low income groups and the old, dictating the method and extent of their travel (Social Exclusion Unit 2003; Clifton \& Lucas, 2004b). These groups often do not have access to private transportation, which forces them to use public transportation as their main means of travel (Doxsey and Spear 1981; Grengs, 2001; Luhrsen \& Taylor, 1997; McLaughlin \& Boyle, 1997; Perrin 1982). For these people, the limiting factor for travel will often be the cost of fares. Yet, under most transit system in North America, the transit dependent are overpaying for their usage of the system. 
Some governments do recognize the need to provide disadvantage groups with financial assistance for fares to enable them to access jobs and opportunities. New Zealand and the United Kingdom for example are national governments that have policies in place to provide free or subsidized fares for low income households and the elderly (Stantec Consulting, 2011). In Canada, it is usually up to municipal governments and their respective transit operators to provide discounted fares to those who need it. Many transit operators do have some policies that allow for discount programs for certain group(s), most notably for students and elders. The TTC for example, offers a 33\% discount $(\$ 2.00$ compared to $\$ 3.00$ ) for single fare purchases and a $20 \%$ discount ( $\$ 108$ compared to \$133.75) for monthly pass to seniors and students (TTC, 2014).

A recent trend is for municipalities and transit operators to identify the need to provide fare discounts to low income individuals as well. Calgary transit was one of the first transit operator to do so with the introduction of low income transit fare in 2005. Low income individuals, based on gross income and family size, are eligible for a discount of $50 \%$ of a normal adult monthly pass (Calgary Transit, 2011). Similar programs can be found in numerous transit operators across the country including Burlington Transit (City of Burlington, 2013), The Hamilton Street Railway Company (City of Hamilton), Grand River Transit (for the Kitchener-Waterloo region) (Grand River Transit), Guelph Transit (City of Guelph), and Regina Transit (City of Regina), all of whom offer low income individuals a discount of $50 \%$ or more of an adult monthly pass.

Yet, some operators are beginning to question the merits of discount programs for disadvantaged groups. Calgary Transit, for example, while understanding the importance of affordable transit service to disadvantaged groups in helping them overcome barriers 
to jobs and opportunities also recognize the high cost of subsides programs. The discounts of certain groups were being paid for by other passengers and this directly impacted the transit operator's goal of reaching a certain revenue/cost ratio (Calgary Transit, 2011). Similarly, Edmonton Transit System recognized a need to ensure affordable access to transit for all but can also foresee rising costs to operate transit as a problem (Edmonton Transit System, 2011). The TTC has flatly rejected calls for further discounts for seniors, families and low income riders, arguing that it is not their job to address social issues and such discounts would add to budget pressures (Spurr, 2013). All these operators recognize the need for a more equitable fare pricing strategy that allows for high levels of accessibility to transit for disadvantaged groups while at the same time not placing a burden on other transit users and taxpayers. Fortunately, there exist a solution that satisfies both criteria and it lays in changing how fares are charged such that a fair fare can be achieved.

\subsection{Transit Fares: Flat and Differentiated pricing}

Transit fares can be of two types: flat fares and differentiated fares. A system that uses a flat fare pricing strategy charges users the same fee for using the entire system, regardless of time or distance of usage. A differentiated fare pricing strategy on the other hand charges users based on the time of usage or distance travelled or a combination of both. The three major differentiated fare systems are time-based, zone-based, and distance-based. Time-based fare systems differentiate fares based on the time that a passenger uses a system. Typically, fares under this system are categorized into peak and off-peak hours. Zone and distance-based fare systems exact fees based on distance 
travelled. Systems under zone-based fares operate under zones; as passengers passes from one zone to another, a surcharge is applied. Distance-based fare systems are more straight-forward and charge based on a per miles/kilometer basis (Cevero, 1990; Transportation Research Board, 2003). A majority of transit operators in North America utilize a flat fare pricing strategy: the MTA (New York City), Chicago Transit Authority, and TTC, to name a few (Metropolitan Transportation Authority; Chicago Transit Authority; Toronto Transit Commission). Only a few operators in North America have implemented differentiated fares: King County Metro, transit operator for the Greater Seattle area, for example, charges different fares based on off-peak and peak hours (King County Metro, 2011); TransLink, transit operator for the Greater Vancouver Area bases fares on zones of service (TransLink); and Bay Area Rapid Transit, transit operator for San Francisco, prices fares based on distance travelled (Bay Area Rapid Transit). Unlike North America, a majority of European transit systems utilize zone-based pricing strategies for fares. London's Underground (Transport for London), Berlin's Berliner Verehrsbetriebe (Berliner Verehrsbetriebe), and Copenhagen Metro (Visit Copenhagen) are notable examples of such systems. A majority of Asian transit operators on the other hand utilize distancebased pricing strategies for fares. Hong Kong's Mass Transit Railway (Mass Transit Railway), Tokyo Metro (Tokyo Metro), and Taipei Metro (Taipei Metro) are notable examples of such systems.

The advantages of a flat fare system are that it is simple to implement by transit operators, easy to understand by passengers, and offers ease of collection and payment (Cevero, 1990; Koski, 1992). Yet, flat fares are rarely considered "fair fares" - fares that offer efficiency in that users pay for the cost that equals to amount of benefit they receive 
from services used and equitability in that the fares take into account user's ability to pay (Cevero, 1981). On the contrary, differentiated fare systems are those that are seen to be fair, offering efficient and equitable pricing (Transportation Research Board, 2003).

\subsection{Flat Fares and Equability}

Indeed, literature has long theorized that flat fares are neither efficient nor equitable (Vickrey 1973; Harrison \& Douglas, 1974; Altshuler, 1979; Erba, 2005). The cost of running a transit system depends on the time of day and distance the system serve. More resources, such as additional employees to service extra demand from passengers and fuel for transit vehicles, are required to operate a system during peak hours and for longer routes (Cevero, 1981). The cost of delivering passengers during peak hours and/or for further trips is higher than delivering those that travel during offpeak hours and shorter trips. Under flat fares, the extra cost of running the transit system for those passengers who travel during peak periods and/or for longer trips would not be accounted for. These passengers would be underpaying for their usage of the system while short distance, off-peak passengers (who usage cost is less), would overpay for their usage of the system. This creates an inequality between users as one group (short distance, off-peak passengers) are subsidizing the cost of another group of users (long of long distance, peak-hour passengers)

The existing literature has also demonstrated that disadvantaged groups, such as low income households, females, non-car owners, and recent immigrants, are those who travel shorter distances (Cevero, 1981; Cevero, 1990; Currie \& Delbosc, 2011; Meyer, 1965) and more often during non-peak hours on trips (Cevero, 1981; Giuliano, G., 2005). 
For example, Taylor, Garrett \& Iseki (2000) analyzed United States' 1995 Nationwide Personal Transportation Survey and found that low income persons make less trips, travel shorter in distance and less likely to travel during peak periods compared to other income groups. Another study researching the commute distance in Toronto concluded that those who are recent immigrants, those who are aged between 30 and 44, and males have the longest commute distances. The study also found that as household income increases, so does commuting distance (Axisa et al., 2011).

Disadvantaged groups are more likely to travel during nonpeak hours because they are more predisposed to be employed part-time and in the service sector, and have training, and services that require them to travel throughout the span of a day (Walker, 2014). They are also more likely to travel short trips because disadvantage groups, especially low-income households, are found to concentrate in central cities where things are closer together and do not require long trips (Pucher \& Renne, 2003).

Several studies have established evidence of the flat fare inequality phenomenon in transit systems across the United States. Rock (1975), for example, found that distance related price inequities in Chicago's transit system caused a redistribution of income from blacks to whites. Cevero (1981) found that flat fare pricing structures in three California transit agencies had modest inequities when compared to differentiated pricing system. Cevero and Waches (1982) found that off-peak users were found to cover 56 percent of their costs under flat fares compared to 37 percent for peak hours users in Los Angele's transit system. In another study of Los Angele's system, Luhrsen \& Taylor (1997) found that the flat fare structure used in the system is neither efficient or effective nor equitable. 
The flat fare structure applied worked against those who were transit dependent - the poor, non-white, young or old and female - as they pay relatively more for transit on a per mile basis, covering a larger portion of transit operation costs.

Evidence of similar studies on fare equality amongst passengers in Canadian transit systems could not be found however. There exists minimal analysis on the equitability of transit fare pricing structures in Canada in literature. An exception is a recent report by the Residential and Civil Construction Alliance of Ontario on financing transportation and transit in the Greater Toronto Area (Kitchen \& Lindsey, 2013). On transit funding, the report concluded that flat fares are inefficient and inequitable as it goes against the benefits-received principle and recommended transit operators to adopt a more efficient and integrate fare structure with zonal and peak/off peak fare pricing in order to provide for fairness and equity to passengers (Kitchen \& Lindsey, 2013). Some transit operators have explored the possibility of using a distance-based and/or timebased fares. In practice, Translink is the only major transit operator in Canada to implement a zone-based fare strategy. Calgary Transit considered zone and time-based fares in the past, but did not adopt such policies due to administrative, costs, technology, and public support issues. New initiative to replace paper based tickets and passes with electronic smart cards however will allow Calgary Transit to reconsider distance or destination based fares (Calgary Transit, 2011). Similarly, TTC is looking to overhaul fare policies through the adaptation of the PRESTO farecard system, which will allow them to consider distance and time-based fares in the future (Toronto Transit Commission, 2013) 


\subsection{Purpose of MRP}

The aim of this Major Research Project (MRP) is to start bridging the literature gap by evaluating the fare equality between socio-demographic groups of passengers for the Toronto Transit Commission (TTC)'s subway system. TTC is the public (and the only) transit operator for the City of Toronto and employs a flat fare pricing strategy for all its transit systems. Based on the literature review, it is predicted that disadvantaged passengers including the young and old, female, part time workers/the unemployed, low household income individuals, immigrants, non-car owners, are subsidizing other passengers (i.e. middle aged, male, full time workers, high household income individuals, residents, and car owners) for using the subway system under the current flat TTC fare pricing structure. 


\subsection{Methodology}

This section discusses the methodology of the proposed research. A detailed explanation of the methods used, which includes data collection and data analysis are described here.

The design of this study emulated parts of the methodology used in Cevero (1981). In the study, Cevero analyzed three California transit operators in order to draw conclusions on the efficiency and equity factors of alternative transit pricing strategies. He collected the transit operators' revenue and cost data and conducted on-board ridership surveys that gathered information on passenger's fare payments, distances and times of travel, and demographic characteristics such as age, gender, ownership, and family income. Through a quantitative analysis of the data, Cevero was able to correlate variables and establish the level of efficiency and fairness of each pricing strategies used by each transit operators.

This study's research objective is to explore if there are inequities between those who uses TTC's subway system and if so who benefits under the flat fare pricing strategy. Equality is examined by drawing correlation between various demographic variables with distance travelled, expressed as rate per kilometer travelled (RPKM) and time of day the system was used. The hypothesis of the study is that the flat fare pricing policy employed by the TTC creates inequity amongst different demographic groups of passengers and it is likely that the pricing policy benefits those who do not belong to disadvantaged groups, such as middle aged individuals, males, and those from high income households. 


\subsection{Data Collection}

The Toronto Transit Commission (TTC) is the main transit operator for the City of Toronto. The TTC operates subway, streetcar, and bus systems in the city, serving 1.7 million customer journeys every workday. In 2013, a reported 515 million passenger trips were taken, making the TTC the third largest transit operator in North America (Toronto Transit Commission, 2013). Like many other transit systems in North America, the TTC uses a flat pricing structure.

Questionnaire surveys were used to collect data from subways passengers. The surveys were divided into two parts: Trip Information and Demographic Information. Intercept surveys were conducted at entrances of three pre-determined subway stations - Queen's Park, Queen, and Bloor-Yonge stations - during an off-peak period - mid-day, between 1:00pm and 4:00pm - and during peak period - the evening peak, between 4:00pm and 7:00pm. The three subway stations were selected to limit the scope of the study to passengers who travel from Toronto's downtown core to locations within the City. In other words, this survey only explored transit equity for those who live, work, or travel to Downtown Toronto and/or used downtown stations as transfer stations. These parameters were selected as so due to the time, resources and manpower available. A short time frame as well as a lack of resources and manpower meant that the study had to be limited in size and to the selected locations. This topic is explored more in-depth in the Limitation section of the study.

Subway passengers were randomly selected to complete the surveys. To ensure a strong random selection process, passengers were not screened for any particular 
attribute and only every fifth passenger entering the stations were selected. Only passengers entering the subway stations were selected to participate. All the stations selected are located within Toronto's downtown core and the stations' vicinity are concentrated with jobs and homes. At the time of the data collection (i.e. the afternoon/peak hour), passengers on the transit system were likely returning home. Passengers who left a station were likely be those who live in the vicinity of the station, meaning their social-demographic characteristics were similar. Passengers who entered a station, on the other hand, were likely be those living elsewhere in the city, which meant they may had more diverse backgrounds. Thus collecting data from passengers who entered a station allowed for a greater chance of a more diverse population sample.

The type of data collected from the surveys included: time of day system was used, the distance travelled by passenger, and demographic information on age, gender, occupation and employment status, income, citizenship status and car ownership. A sample of the survey used can be found in Appendix A.

\subsection{Data Analysis}

First, distance travelled between origin stations and destination stations were calculated using geographic information system (GIS) software ArcMap 10.1. A map of the TTC's subway system was extracted from CanMap RouteLogisitics (DMTI Spatial Inc.), and measurements of the distance (in kilometers) between stations were taken. The measurements assumed that the passenger took the shortest, most direct path on the subway system to his or her destination. For example, if the passenger's origin station was Queen's Park and destination station was Lawrence, it was assumed that he or she 
would take the Yonge-University line north to St. George station, transferred to the Bloor line to Bloor-Yonge station and then transferred again back onto the Yonge-University line to Lawrence rather than just taking the Yonge-University line south to avoid transfers. Resulting distance data was inputted into SPSS statistical software. As mentioned above distance travelled was expressed by the variable rate per kilometre travelled (RPKM). To calculate this variable, the fare amount passengers pay ( $\$ 3$ for all passengers since it is a flat fare) is divided by the distance they travelled (i.e. RPKM $=\$ 3 /$ distance travelled).

Other information gathered from the surveys were also inputted into SPSS. Several steps were taken to ensure that the data could be analyzed by the program. Nonnumerical responses were coded appropriately. Gender, for example were gathered such that those surveyed answered "male" or "female". Coding was used to convert "male" to 1 and "female" to 0 . This method was performed for time of travel, employment status, household income, residency in Canada, and car ownership.

Linear regression analysis was used to draw correlation between the various demographic data with RPKM and time of usage. Relationships are represented by an equation or model that connects response or dependent variable with one or more predictor or independent variable. The mathematical expression takes the following form:

$$
Y=\beta_{0}+\beta_{1} X_{1}+\beta_{2} X_{2}+\cdots \beta_{p} X_{p}+\varepsilon
$$

Where $Y$ is the dependent variable (in this case, RPKM), $X$ 's are the independent variables and $\varepsilon$ is random error that accounts for failure of the model to fit the data provided, $\beta s$ are the regression parameter or coefficient that tells the direction and 
strength of relationship between $Y$ and $X$ as determined by the data (Chatterjee et al. 2000).

Linear regression assumes the dependent and independent variable exhibits and linear relationship. Bivariate linear regression and multivariate linear regression were used to correlate various demographic data with RPKM. A bivariate linear regression correlates one dependent variable with one independent variable at a time. For example, a model built from bivariate linear regression correlates RPKM with gender. A multivariate linear regression correlates between one dependent variable and two or more independent variables. For example, a model that correlates RPKM with gender and age. In this study, a $95 \%$ confidence internal (i.e., $\alpha=0.05$ ) was used to identify statistical significance of the observed associations. At $p>0.05$, then the null hypothesis cannot be rejected which would suggest that there is no relationship between the dependent variable and independent variable. Alternatively if $p<0.05$, then the null hypothesis should be rejected, meaning there exists a statistical relationship between the dependent variable and independent variable.

The direction (i.e. positive or negative) of the coefficients are useful in describing the relationship between the dependent variable and independent variable. The direction will mean different things in a case-by-case basis however. For this study, as an example, a positive coefficient resulting from a regression analysis between RPKM and age means as age increases, the RPKM increases with it (in other words, the older one is, the more one pays per $\mathrm{km}$ travelled). For other variables, a positive coefficient between: RPKM and gender would mean men paid more per kilometer travelled; RPKM and employment would mean full time workers paid more per kilometer travelled; RPKM and income would 
mean the higher the household income earned, the more fares paid per kilometer travelled; RPKM and residency in Canada would mean the longer you lived in Canada the more you paid per kilometer travelled; RPKM and car ownership would mean those who owned a car would be paying more per kilometer travelled.

Logistic regression is used for the analysis of dichotomous dependent variables (that is, variables that only have two possible values) (Chatterjee et al., 2000; Wuensch, K.L., 2014). A simple logistic model is based on a linear relationship between the natural logarithm of the odds of an event happening and an independent variable. The mathematical expression takes the following form:

$$
L=\ln \left(\frac{p}{1-p}\right)=\beta_{0}+\beta_{1} X_{1}+\beta_{2} X_{2}+\cdots \beta_{p} X_{p}+\varepsilon
$$

where $L$ represents the logarithm of the odds of an event occurring, $p$ the is probability of successes, $\beta s$ are the regression parameter or coefficient that tells the direction and strength of relationship between the dependent and independent variables, and $\varepsilon$ is the random error. Written in terms of the probability of one of the two dependent variable occurring $(p)$, the mathematical expression takes the form (Chatterjee et al., 2000; Katenka, 2012):

$$
p=\frac{e^{\beta_{0}+\beta_{1} X_{1}+\beta_{2} X_{2}+\cdots \beta_{p} X_{p}+\varepsilon}}{1+e^{\beta_{0}+\beta_{1} X_{1}+\beta_{2} X_{2}+\cdots \beta_{p} X_{p}+\varepsilon}}
$$

A bivariate logistic regression correlates between one dependent variable and one independent variable while a multivariate logistic regression correlates between one dependent variable and two or more independent variables. As with linear regression, the p-value is used to observe correlation between the dependent and independent variable. 
The type of relationship between the dependent and independent variable is observed through odds ratio, $\exp (\mathrm{B})$, however. Odds ratio compares the odds the dependent variable occurring as the independent variable increases or decreases by a unit of one. An odds ratio of 2 for example, means that the probability of the dependent variable occurring is twice as likely as the independent variable increases by 1 . An odds ratio of 0.5 , on the other hand, means that the probability of the dependent variable occurring is half as likely as the independent variable increases by 1 . Odds ratio of 1 means there exist no correlation between the dependent and independent variable. For this study, as an example, an odds ratio of 1.1 resulted from a logistic regression analysis between time of use and age. This means that the probability of a passenger using the subway system during peak hours is higher (by a factor of 1.1) as age increases by 1 year.

Linear bivariate regression and linear multivariate regression were used to correlate age, gender, income, employment status, citizenship status, and car ownership, with RPKM. When using linear bivariate regression, models were ran such that the various demographic data along with time of use were inputted individually as independent variables with RPKM as the dependent variable. With linear multivariate regression, all demographic variables along with time of use were inputted as independent variables with RPKM as the dependent variable. To show that middle-aged, males, full-time workers, individuals from high-income households, non-immigrant, and those who own a vehicle are those who are benefiting (i.e. paying less per $\mathrm{km}$ travelled/travelling longer distances), then the coefficient of age, gender, employment status, household income, residency in Canada, and vehicle ownership must be all negative and have a statistical association at $\alpha=0.05$ or less. 
Bivariate and multivariate logistic regressions were used to correlate age, gender, income, employment status, citizenship status, and car ownership, with time of use (since this variable only have the option of off-peak hours and peak hours). When using bivariate logistic regression, models were ran such that the various demographic data were inputted individually as covariables and time of use as the dependent variable. With the multivariate logistic regression, all demographic variables along with time of use were inputted as covariables with time of use as the dependent variable. $95 \%$ confidence intervals were computed for each analysis. To show that middle-aged, males, full-time workers, individuals from high-income households, non-immigrant, and those who own a vehicle are those who are benefiting (i.e. travelling during peak hours), then the odds ratio of age, gender, employment status, household income, residency in Canada, and vehicle ownership must have a value over 1 and have a statistical association at $\alpha=0.05$ or less.

Fare equity was also assessed by evaluating the severity of subsidization occurring between passengers based on distance travelled. In a perfectly equitable system, every passenger would be paying the same amount per kilometer travelled. Inequity occurs when some passengers are paying more per kilometer travelled than others. The assessment was based on a ratio between the passengers subsidizing (i.e. when he or she paid more than the average cost of using the system) and passengers being subsidized (i.e. when he or she paid less than the average cost of using the system). The average cost of using the system was calculated by dividing the fare (\$3) by the average distance travelled by the respondents (i.e. total length travelled by respondents/total respondents). Number of respondents who paid more and paid less were counted. 


\section{$\underline{4.0 \text { Results }}$}

This section presents the results of the study. The first part provides a description of the variables that were surveyed. The second part presents a descriptive analysis of the socio-demographic and trip characteristic data gathered, while the third part provides the results of the statistical analysis.

\section{$\underline{4.1 \text { Survey Analysis }}$}

Table 4.1 provides a summary of the various socio-demographic and travel characteristics data gathered from the study.

Table 4.1: Summary of socio-demographic and travel characteristics data

\begin{tabular}{|c|c|c|c|}
\hline Variable & Categories & $\begin{array}{l}\text { Number of } \\
\text { respondent }\end{array}$ & Percentage \\
\hline \multirow[t]{2}{*}{ Time of travel } & Off-peak hours & 46 & $48.9 \%$ \\
\hline & Peak hours & 48 & $51.1 \%$ \\
\hline \multirow[t]{3}{*}{ Purpose of trip } & Work trip & 34 & $36.2 \%$ \\
\hline & Non-work trip & 57 & $60.6 \%$ \\
\hline & Did not respond & 3 & $3.2 \%$ \\
\hline \multirow{3}{*}{ destination city } & Within the City of Toronto & 83 & $88.3 \%$ \\
\hline & Outside City of Toronto & 10 & $10.6 \%$ \\
\hline & Did not respond & 1 & $0.1 \%$ \\
\hline Distance & Less than $5 \mathrm{~km}$ & 32 & $34 \%$ \\
\hline \multirow[t]{3}{*}{ travelled } & $5 \mathrm{~km}$ to $10 \mathrm{~km}$ & 22 & $23.4 \%$ \\
\hline & $10 \mathrm{~km}$ to $15 \mathrm{~km}$ & 31 & $33 \%$ \\
\hline & More than $15 \mathrm{~km}$ & 8 & $8.5 \%$ \\
\hline Rate per & Under $\$ 0.5$ & 55 & $58.5 \%$ \\
\hline kilometer & $\$ 0.5$ to $\$ 1$ & 15 & $16 \%$ \\
\hline \multirow[t]{3}{*}{ travelled } & $\$ 1$ to $\$ 1.5$ & 7 & $7.4 \%$ \\
\hline & $\$ 1.5$ to $\$ 2$ & 6 & $6.4 \%$ \\
\hline & Over $\$ 2$ & 10 & $10.6 \%$ \\
\hline \multirow[t]{3}{*}{ Age } & Under 30 & 49 & $52.1 \%$ \\
\hline & 30 to 39 & 24 & $25.5 \%$ \\
\hline & Over 40 & 21 & $22.3 \%$ \\
\hline \multirow[t]{2}{*}{ Gender } & Female & 55 & $58.5 \%$ \\
\hline & Male & 37 & $39.4 \%$ \\
\hline Employment & Full time & 70 & $74.5 \%$ \\
\hline Status & Part time & 23 & $24.5 \%$ \\
\hline
\end{tabular}




\begin{tabular}{llrr} 
Household & $<\$ 15,000$ & 12 & $12.8 \%$ \\
Income & $\$ 15,000$ to $\$ 30,000$ & 4 & $4.3 \%$ \\
& $\$ 30,000$ to $\$ 45,000$ & 19 & $20.2 \%$ \\
& $\$ 45,000$ to $\$ 60,000$ & 11 & $11.7 \%$ \\
& $\$ 60,000$ to $\$ 75,000$ & 11 & $11.7 \%$ \\
Residency in & $>\$ 75,000$ & 16 & $17 \%$ \\
Canada & $<2 y r s$ & 2 & $21.2 \%$ \\
& $2-5 y r s$ & 9 & $9.6 \%$ \\
& 6-9yrs & 9 & $9.6 \%$ \\
Transit & $>10 y r s$ & 74 & $78.7 \%$ \\
spending per & Less than $\$ 10$ & 5 & $5.3 \%$ \\
month & $\$ 10$ to $\$ 30$ & 8 & $8.5 \%$ \\
& $\$ 30$ to $\$ 50$ & 6 & $6.4 \%$ \\
& $\$ 50$ to $\$ 70$ & 7 & $7.4 \%$ \\
Car ownership & Over $\$ 70$ & 64 & $68.1 \%$ \\
& No & 56 & $59.6 \%$ \\
& Yes & 37 & $39.4 \%$ \\
\hline
\end{tabular}

A total of 93 surveys were collected. Of all the surveys collected, 34 (36.5\%) were from Queen's Park station, $32(34.4 \%)$ were from Queen Station and $27(29 \%)$ were from Bloor-Yonge station. There were 44 (47.3\%) surveys collected during off peak hours and $49(52.7 \%)$ collected at peak hours. Figure 4.1 shows a more comprehensive breakdown of where and when the surveys were collected: 18 surveys were from the off peak hours period while 17 were collected were from the peak hours period were collected at Queen's Park; 17 surveys were from the off-peak hours period while 15 were from the peak hours period at Queen; and 11 surveys were from the off-peak hours period while 16 were from the peak hours period at Bloor-Yonge.

Most surveys were fully complete, however a few were with some missing answers. The most common unanswered question was household income, with a response rate of $79.6 \%$. Other questions had at least a response rate of $90 \%$. For the 
quantitative modelling exercise, incomplete surveys were not used. As a result, the analysis sample size was 69 .

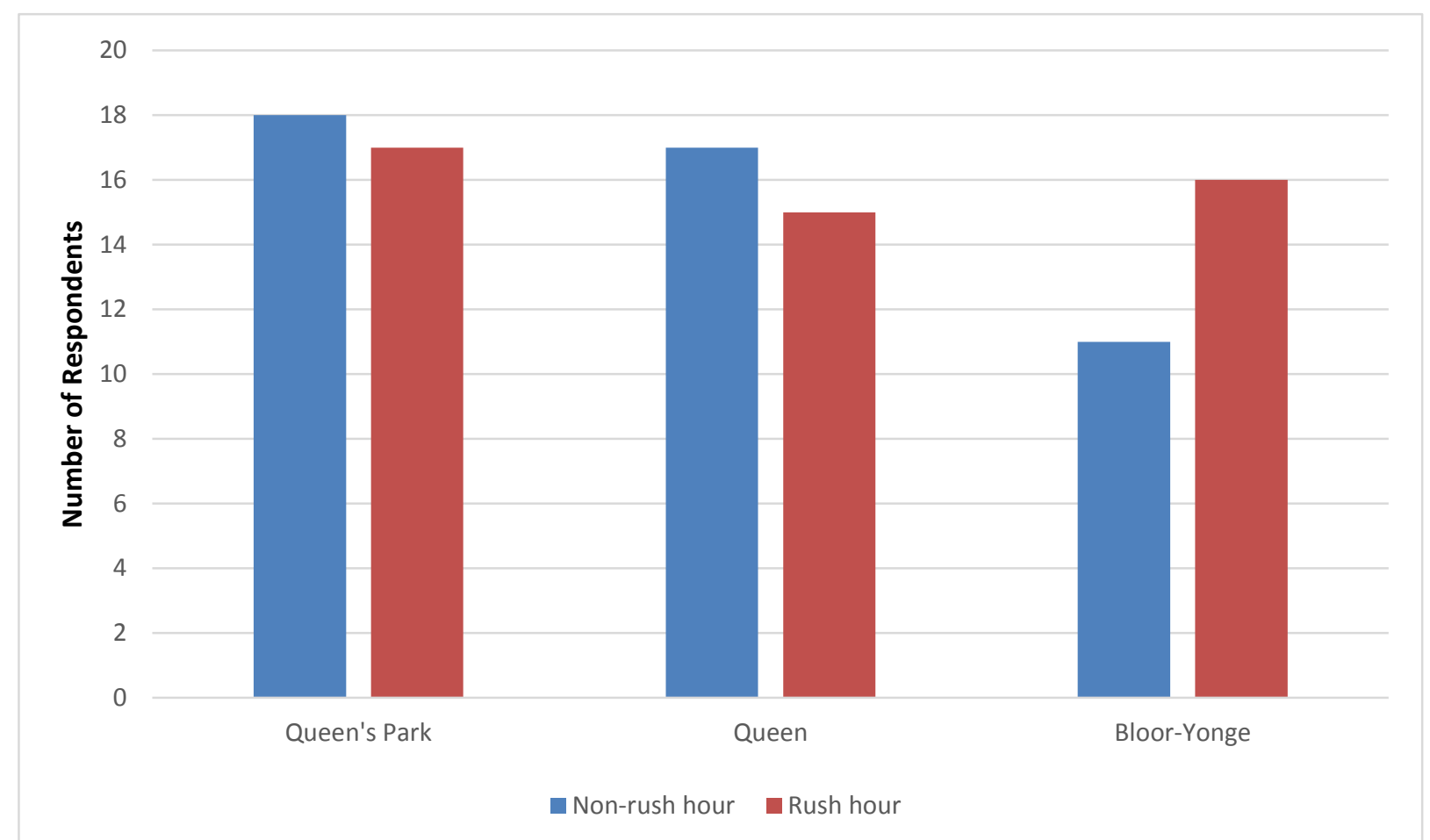

Figure 4.1: Breakdown of the locations and time periods at which surveys were collected

\subsection{Descriptive Analysis}

There were 34 respondents (36.5\%) that were travelling on a non-work trip, 57 (61.3\%) that were travelling on a work trip, and 2 that did not indicate their trip purpose (Figure 4.2). 


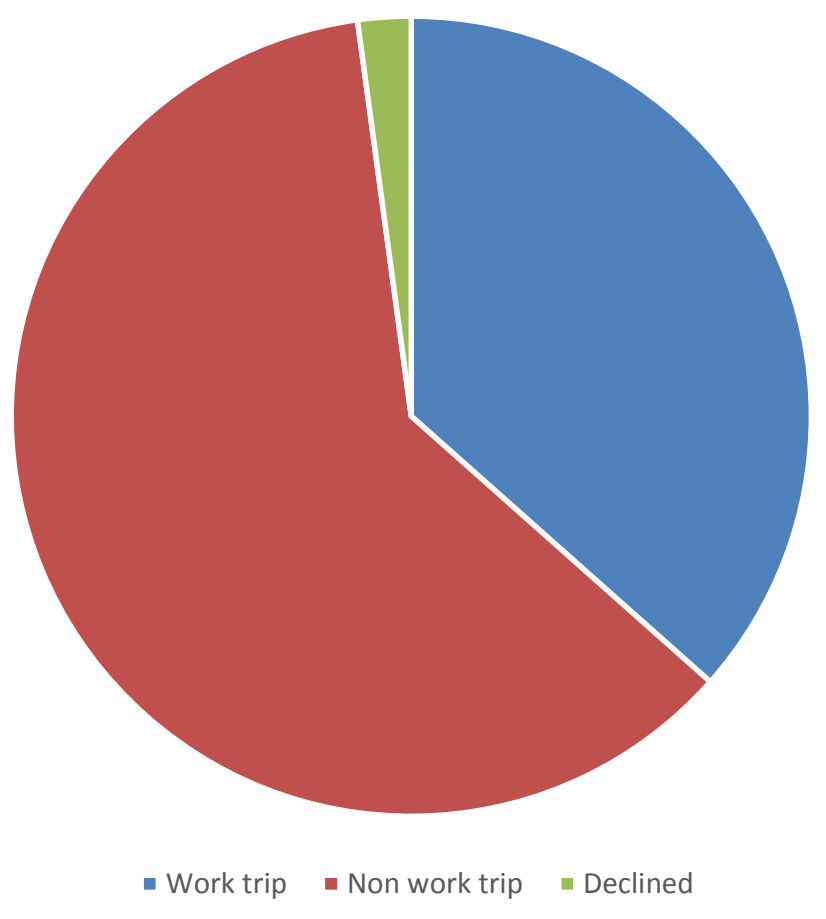

Figure 4.2: Purpose of trip

A majority of those surveyed (83 out of the 93 ) were travelling within the City of Toronto. Others started their trip in Toronto and ended up in the Greater Toronto Area, such as Markham or Newmarket (Figure 4.3) 


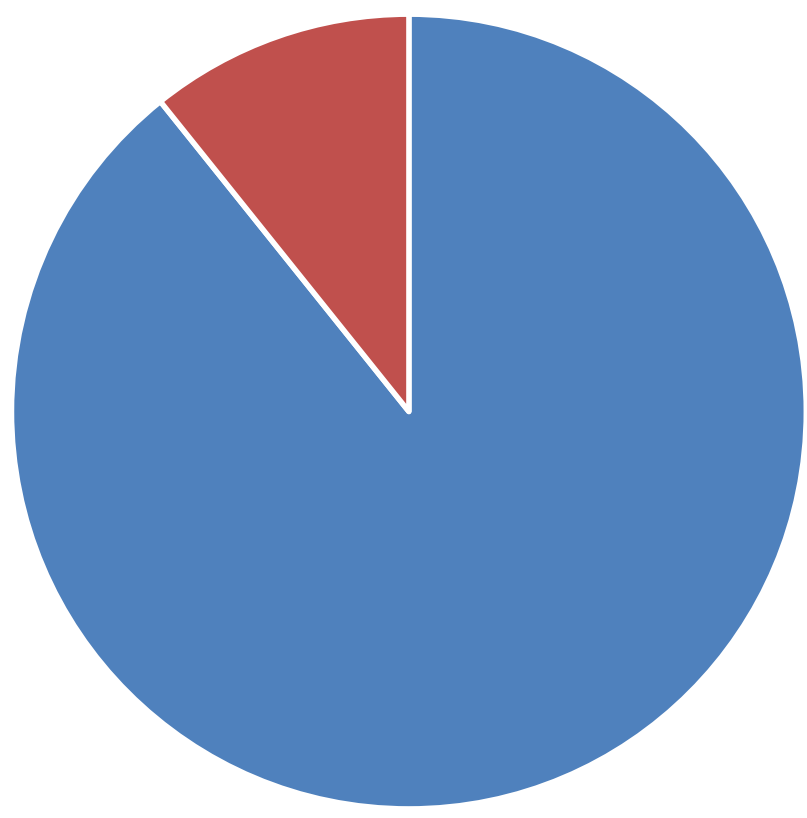

- Within City of Toronto

Figure 4.3 Trip origin and destination city

\subsection{1: Distance Travelled and Fare Paid}

Distances travelled by respondents varied greatly. Trips were as short as $0.76 \mathrm{~km}$, from Queen to Union stations to as far as $25.34 \mathrm{~km}$, from Finch to Kipling stations. Approximately $34.4 \%$ of respondents travelled less than $5 \mathrm{~km}, 23.7 \%$ travelled between $5 \mathrm{~km}$ to $10 \mathrm{~km}, 33.3 \%$ travelled $10 \mathrm{~km}$ to $15 \mathrm{~km}$ and $8.6 \%$ travelled more than $15 \mathrm{~km}$. The results are reflected in Figure 4.4. 


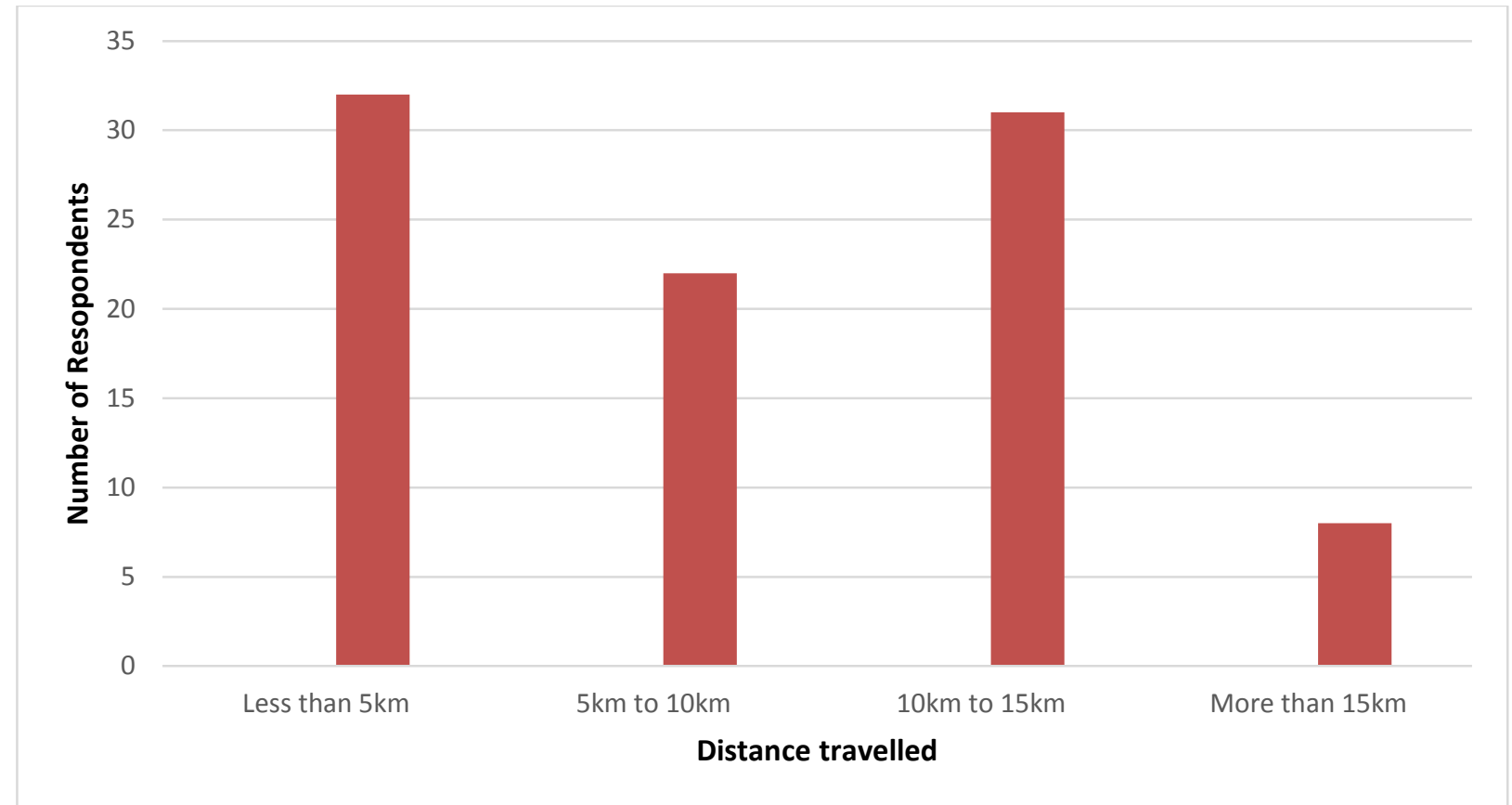

Figure 4.4: Distance travelled on the subway system

Accordingly, the rate at which passengers paid for each kilometer of travel varied greatly as well. Short distance passengers paid as much as $\$ 3.9$ per kilometer travelled while long distance passengers paid as little as $\$ 0.11$ per kilometer travelled. Figure 4.5 breaks down the rate paid per kilometer in four categories and show the number of respondents in each category. A majority of those surveyed paid little per kilometer travelled: 55 (59.1\%) respondents paid under \$0.5 cents per kilometer, 15 (16.1\%) paid $\$ 0.5$ to $\$ 1$ per kilometer, 7 (7.5\%) paid $\$ 1$ to $\$ 1.5$ per kilometer, 6 (6.4\%) paid $\$ 1.5$ to $\$ 2$ per kilometer, and 10 (10.7\%) paid \$2 per kilometer. Figure 4.6 separates rate paid per kilometer into when the respondents travelled. 


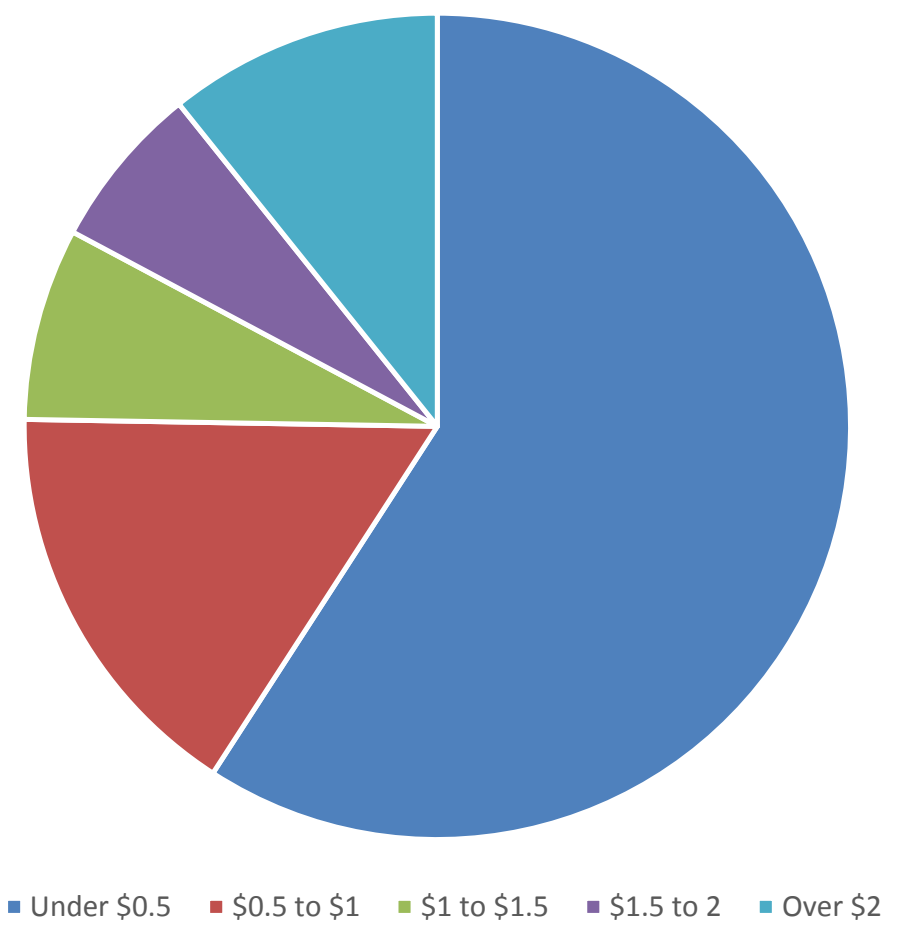

Figure 4.5: Fare paid per kilometer travelled (RPKM)

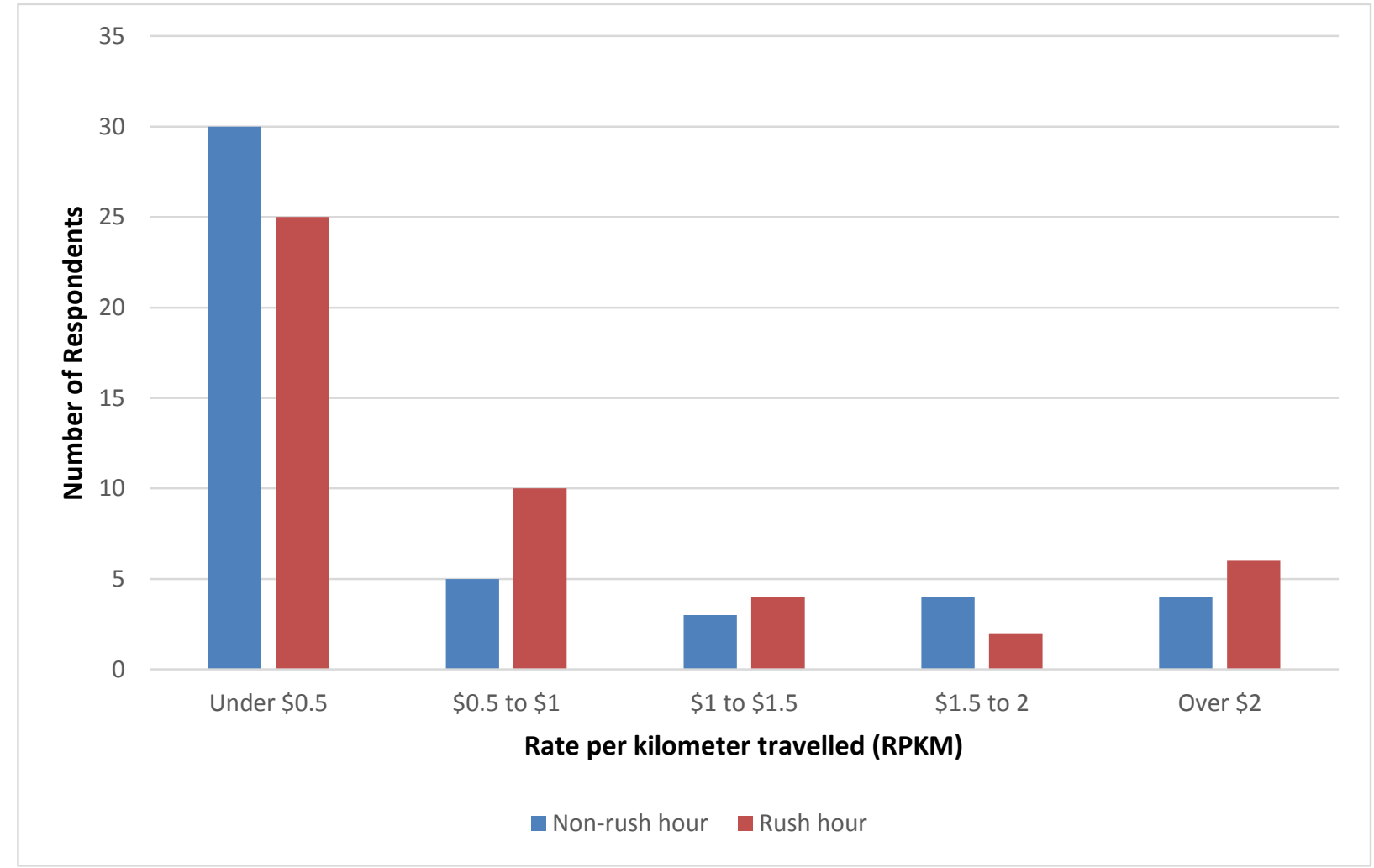

Figure 4.6: Rates paid per kilometer travelled (RPKM), separated by time of usage 
The average cost of use per kilometer was calculated to be $\$ 0.365$. 49 respondents (52.7\%) paid less than the average cost of use per kilometer, and thus were being subsidized by the other 44 respondents $(47.3 \%)$ who paid more than the average cost of use per kilometer.

Respondents, on average, paid $\$ 0.81$ per kilometer travelled during peak hours compared to $\$ 0.7$ per kilometer travelled during off-peak hours. In other words, peak hours respondents travelled shorter distances, and were paying a relatively higher fare during peak hours compared to off-peak hours.

64 participants (68.8\%) spent over $\$ 70$ on transit each month, while $7(7.5 \%)$ spent between $\$ 50$ to 70,6 spent (6.5\%) between $\$ 30$ and $\$ 50,8$ (8.6\%) spent $\$ 10$ to $\$ 30$ a month, 5 (5.4\%) spent less than $\$ 10$ a month, and 3 declined to answer (Figure 4.7).

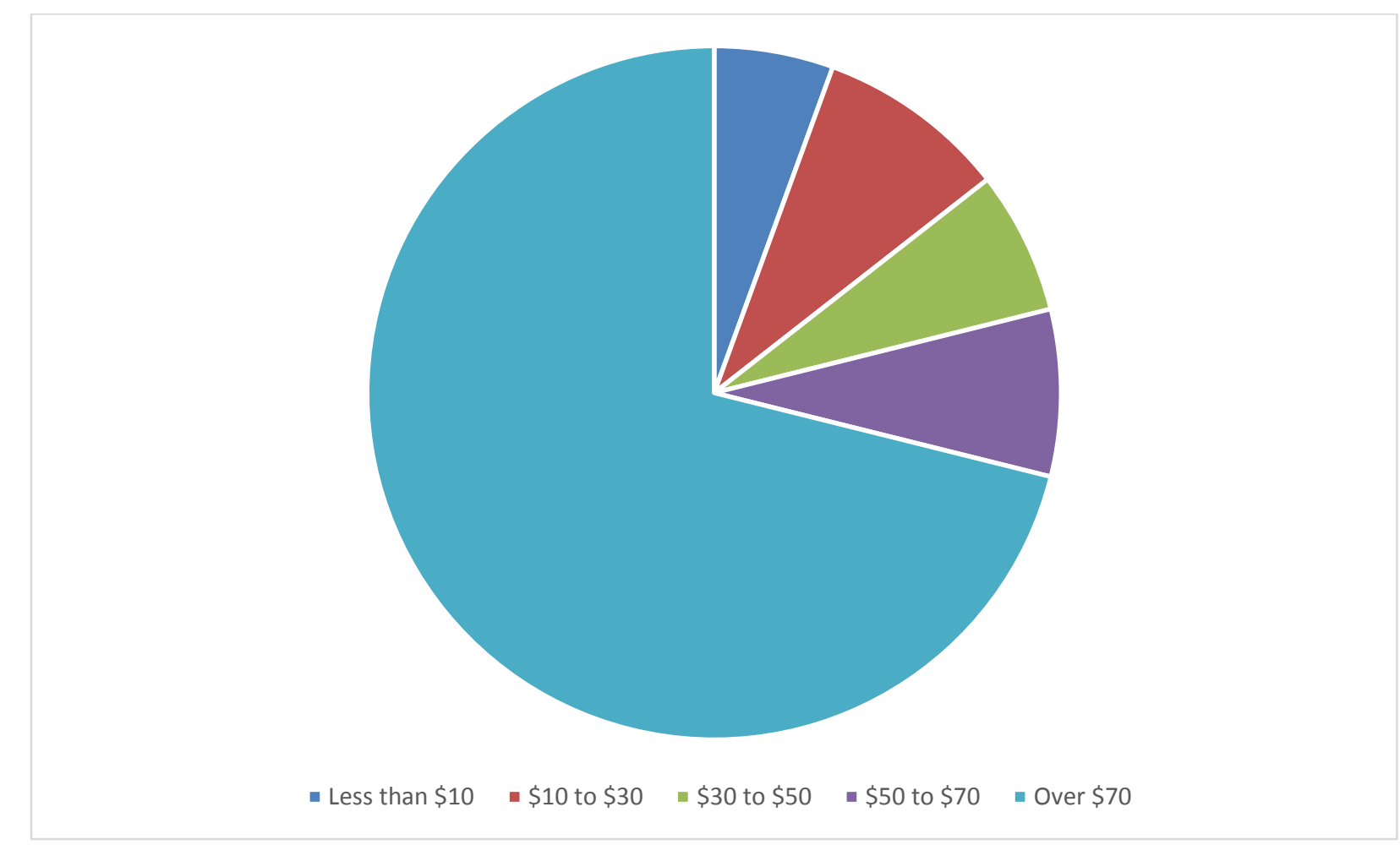

Figure 4.7: Amount of money spent on transit each month 


\subsection{2: Socio-demographic Variations in Subway System Users}

In terms of demographics, most people who were surveyed were $<30$ years of age. Figure 4.8 shows that 49 participants (52.6\%) were under the age of $30,24(25.8 \%)$ were between 30 and 39, while $21(22.5 \%)$ were over the age of $40.55(59 \%)$ of those that were surveyed were female compared to $37(39 \%)$ males (one person declined to state their gender) (Figure 4.9). Participants had a range of different occupations such as students, researchers, and engineers. 70 (75\%) of those surveyed held a full time job while $23(25 \%)$ had a part time job (Figure 4.10$)$.

Household income were somewhat evenly distributed between the categories, with the exception of $\$ 15,000$ to $\$ 30,000.12$ participants (12.9\%) had a household income of less than $\$ 15,000,4(4.3 \%)$ earned between $\$ 15,000$ and $\$ 30,000,19$ earned between $\$ 30,000$ and $\$ 45,000,11(11.8 \%)$ earned between $\$ 45,000$ and $\$ 60,000,11(11.8 \%)$ earned between $\$ 60,000$ and $\$ 75,000$, and 16 (17.2\%) earned more than $\$ 75,000$ (Figure 4.11).

74 participants $(79.6 \%)$ lived in Canada for more than 10 years, $9(9 \%)$ lived in Canada between 6 to 9 years, 9 (9\%) lived in Canada between 2 to 5 years, $2(2.2 \%)$ lived in Canada for less than 2 years, and 1 declined to answer (Figure 4.12). Finally, there were $37(39.8 \%)$ participants that owned a car compared to $56(60.2 \%)$ that did not (Figure 4.13). 


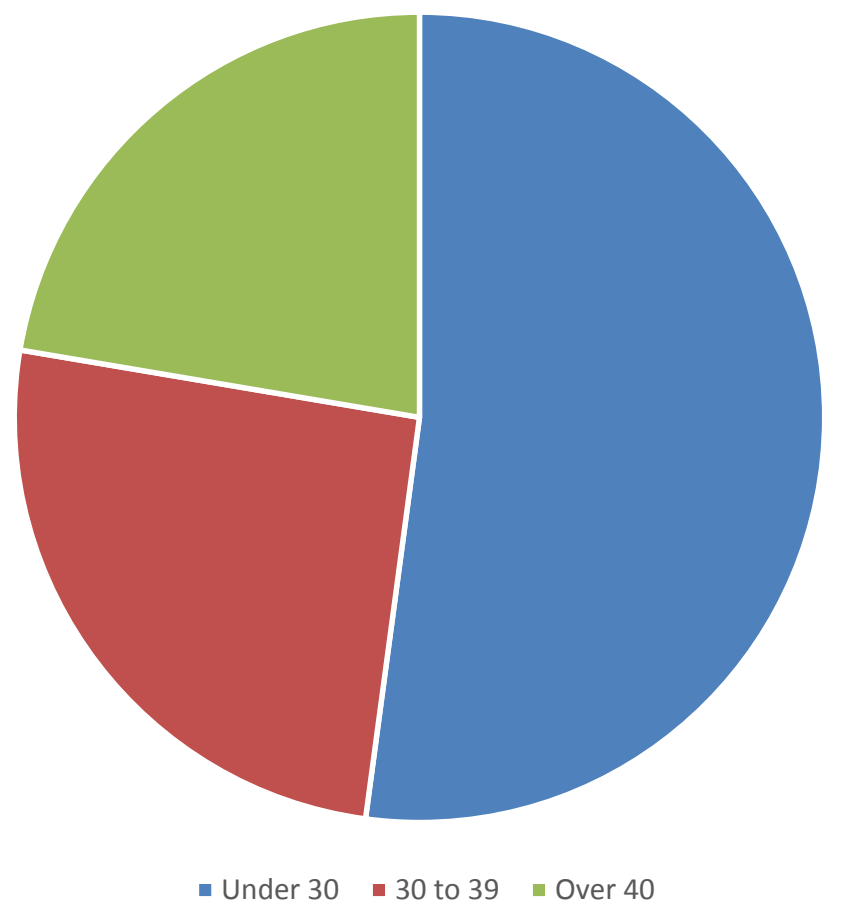

Figure 4.8: Age of subway users

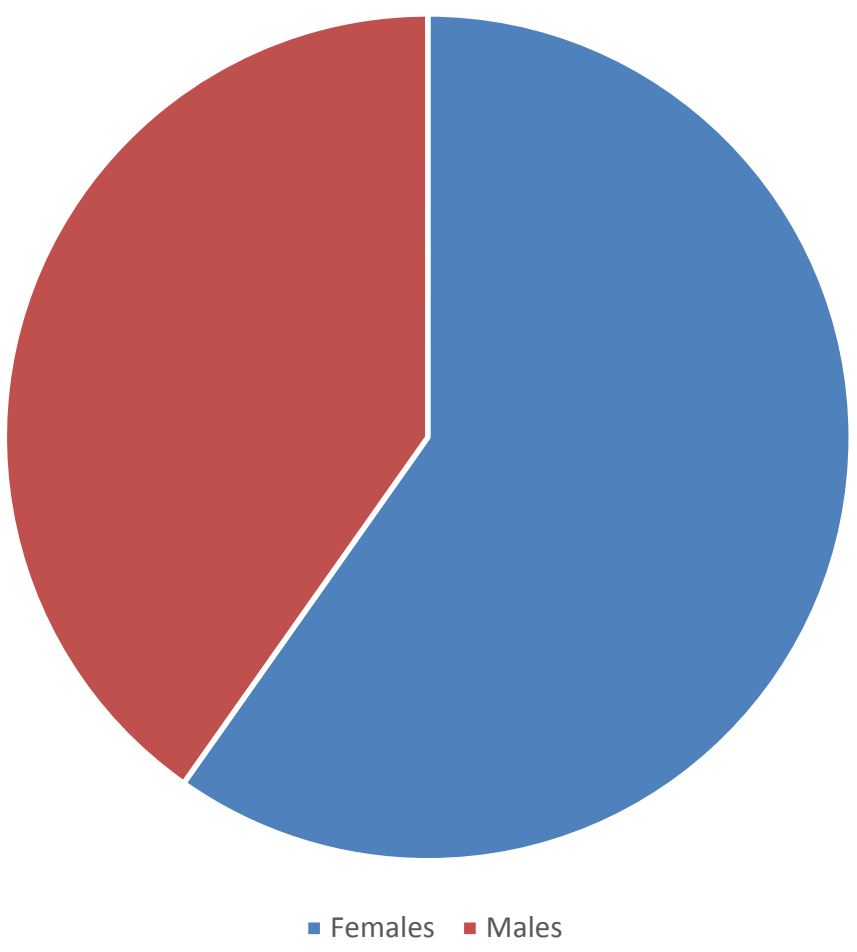

Figure 4.9: Gender of subway users 


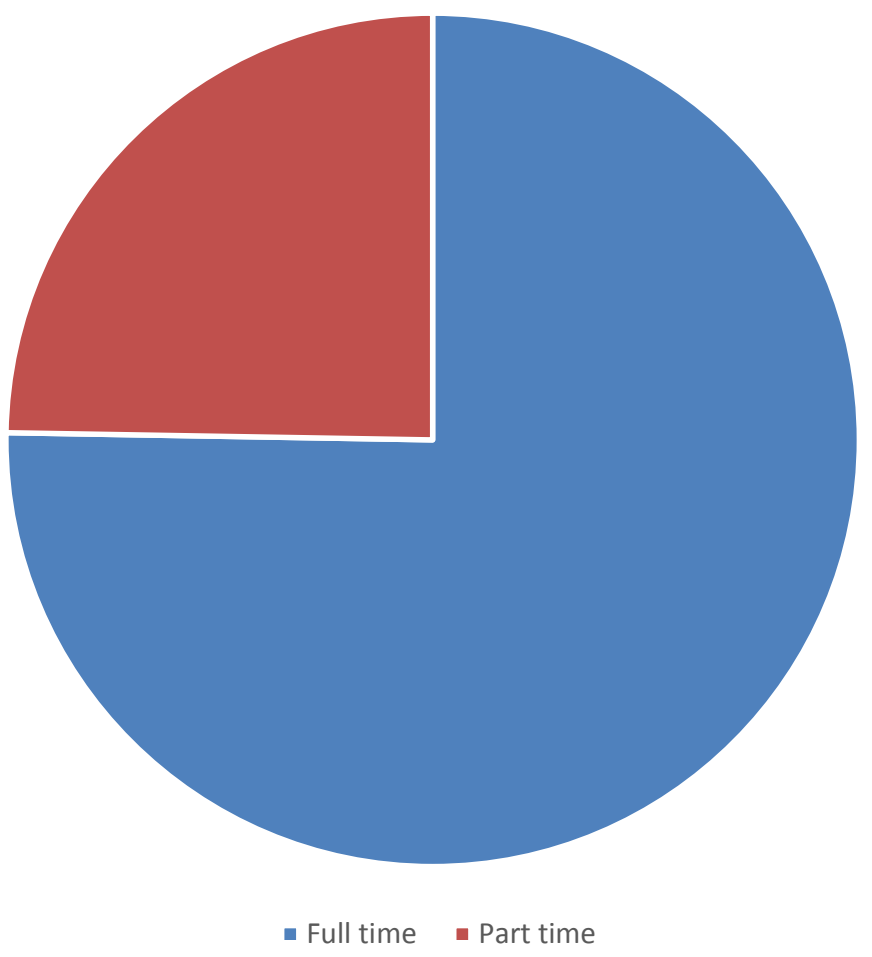

Figure 4.10: Employment status of subway users

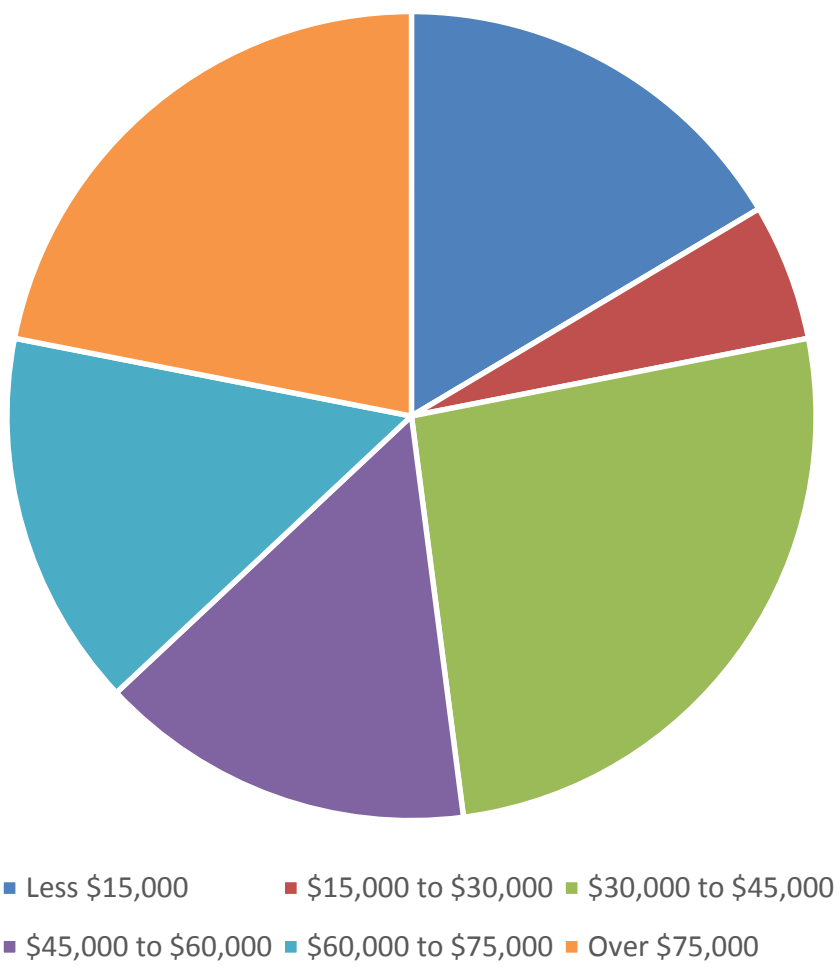

Figure 4.11: Household income of subway users 


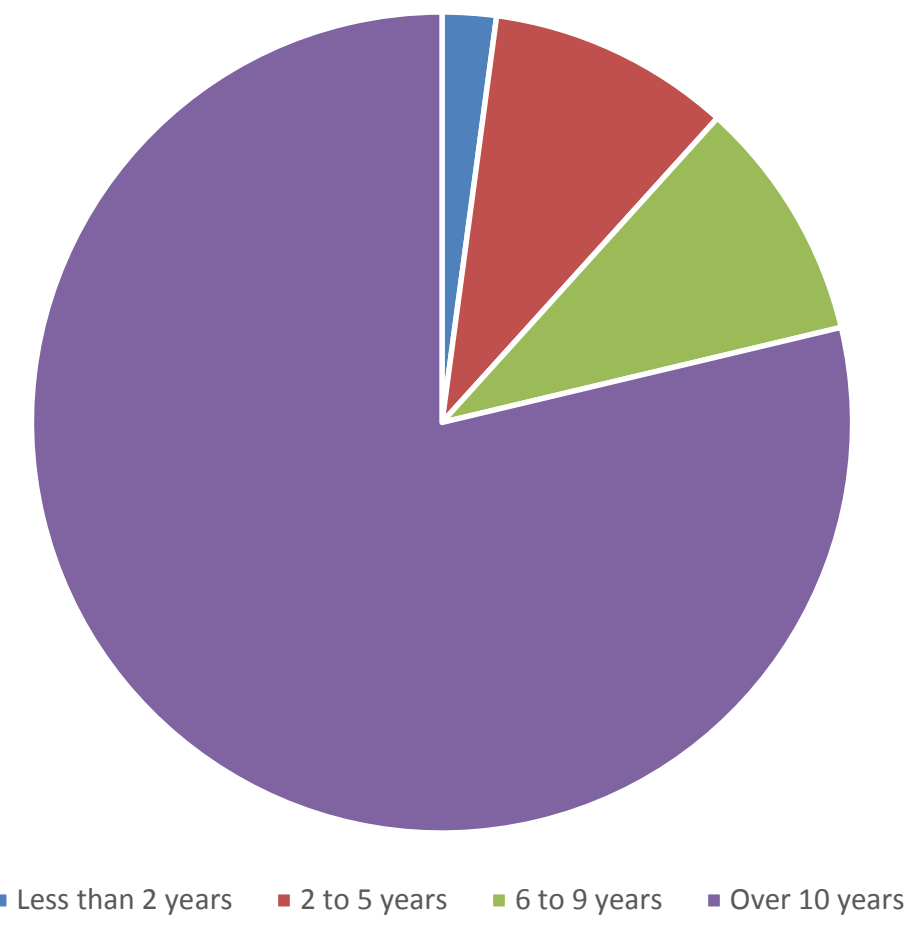

Figure 4.12: The number of years subway users have lived in Canada

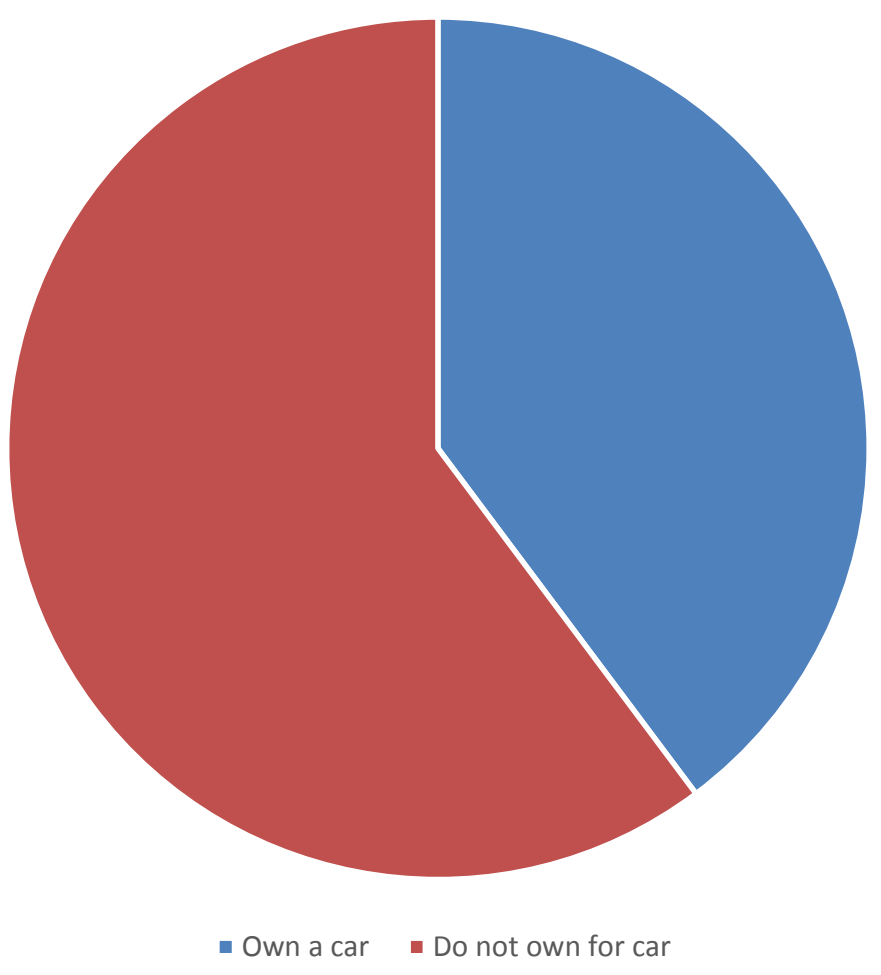

Figure 4.13: Car ownership status of subway users 


\subsection{Statistical Analysis}

Following the analysis of the socio-demographic and travel characteristics data gathered, correlation between variables were drawn using a number of regression models. Table 4.1 summarizes the results of the linear bivariate regression analysis performed. The table lists the coefficient for each variable, standard error, and $p$-value results, as it relates to the correlation between RPKM and time of use, age, gender, employment status, income, residency, and car ownership.

Table 4.2: Results of Bivariate Linear Regression Analysis ( $n=69$ )

\begin{tabular}{|c|c|c|c|c|}
\hline $\begin{array}{l}\text { Dependent } \\
\text { Variable }\end{array}$ & Independent Variable & Coefficient & Standard Error & $p$-value \\
\hline \multirow[t]{14}{*}{ RPKM } & $\begin{array}{l}\text { Time of usage - Peak } \\
\text { hours }\end{array}$ & 0.028 & 0.207 & 0.894 \\
\hline & Age & -0.001 & 0.011 & 0.919 \\
\hline & Gender - Male & 0.462 & 0.200 & 0.024 \\
\hline & $\begin{array}{l}\text { Employment status - Full } \\
\text { time } \\
\text { Income }\end{array}$ & 0.355 & 0.260 & 0.177 \\
\hline & $<\$ 30,000$ & Reference & Reference & Reference \\
\hline & $\$ 30,000$ to $\$ 45,000$ & -0.036 & 0.239 & 0.879 \\
\hline & $\$ 45,000$ to $\$ 60,000$ & -0.103 & 0.281 & 0.716 \\
\hline & $\$ 60,000$ to $\$ 75,000$ & 0.410 & 0.277 & 0.143 \\
\hline & $>\$ 75,000$ & 0.018 & 0.250 & 0.941 \\
\hline & Residency in Canada & & & \\
\hline & $<5 y$ & Reference & Reference & Reference \\
\hline & $6-9 y$ & 0.016 & 0.322 & 0.960 \\
\hline & $>10 y$ & -0.031 & 0.263 & 0.908 \\
\hline & $\begin{array}{l}\text { Car ownership - Owns a } \\
\text { vehicle }\end{array}$ & 0.085 & 0.212 & 0.690 \\
\hline
\end{tabular}

Note: Coefficients in bold are statistically significant at $\alpha=0.05$.

Table 4.2 summarizes the results of the Linear Multivariable Regression analysis performed. Similar to the table 4.1, this table list the coefficient variable, standard error, and p-value results of the correlation between RPKM and time of use, age, gender, employment status, income, residency, and car ownership. 
Table 4.3: Results of Multivariate Linear Regression analysis ( $n=69$ )

\begin{tabular}{lllll}
\hline $\begin{array}{l}\text { Dependen } \\
\text { t Variable }\end{array}$ & Independent Variable & Coefficient & Standard Error & p-value \\
\hline RPKM & Time of use - Peak & -0.127 & 0.235 & 0.590 \\
& hours & & & \\
& Age & -0.005 & 0.012 & 0.675 \\
& Gender - Males & $-\mathbf{0 . 5 0 1}$ & $\mathbf{0 . 2 2 2}$ & $\mathbf{0 . 0 2 8}$ \\
& Employment status - & 0.204 & 0.308 & 0.327 \\
& Full time & & & \\
Income & & & Reference \\
$<\$ 30,000$ & Reference & Reference & 0.781 \\
$\quad \$ 30,000$ to $\$ 45,000$ & 0.099 & 0.352 & 0.2491 \\
$\quad \$ 45,000$ to $\$ 60,000$ & 0.473 & 0.406 & 0.818 \\
$\quad \$ 60,000$ to $\$ 75,000$ & 0.098 & 0.424 & 0.608 \\
$\quad>\$ 75,000$ & 0.205 & 0.398 & \\
Residency in Canada & & & Reference \\
$<5 y$ & Reference & Reference & 0.789 \\
$\quad 6-9 y$ & -0.144 & 0.534 & 0.984 \\
$\quad>10 y$ & -0.009 & 0.446 & 0.751 \\
Car ownership - Owns & 0.77 & 0.241 & \\
a Vehicle & & &
\end{tabular}

Note: Coefficients in bold are statistically significant at $\alpha=0.05$.

Table 4.3 summarizes the results of the bivariate logistic regression analysis performed. The table list the $p$-value and $\operatorname{Exp}(B)$ and $95 \%$ C.I. range.

Table 4.4: Results of Bivariate Logistic Regression Analysis ( $n=69$ )

\begin{tabular}{llll}
\hline $\begin{array}{l}\text { Dependent } \\
\text { Variable }\end{array}$ & Independent Variables & p-value & $\begin{array}{l}\text { Exp(B) with 95\% } \\
\text { C.I. }\end{array}$ \\
\hline Time of use & RPKM & 0.892 & $\begin{array}{l}1.040(0.592- \\
1.825)\end{array}$ \\
& Age & 0.960 & $0.999(0.952-$ \\
& & $1.048)$ \\
& Gender - Male & 0.353 & $0.633(0.242-$ \\
& Employment status - Full time & 0.230 & $1.659)$ \\
& & & $0.469(0.136-$ \\
Income & & $1.614)$ \\
& $\$ 30,000$ & Reference & Reference \\
& & $0.318(0.069-$ \\
& & 0.142 & $1.468)$
\end{tabular}




\begin{tabular}{lll}
$\$ 45,000$ to $\$ 60,000$ & 0.137 & $0.323(0.073-$ \\
& & $1.422)$ \\
$\$ 60,000$ to $\$ 75,000$ & $\mathbf{0 . 0 2 6}$ & $\mathbf{0 . 1 3 6 ( 0 . 0 2 4 -}$ \\
& & $\mathbf{0 . 7 8 6})$ \\
$>\$ 75,000$ & 0.973 & $0.970(0.168-$ \\
& & $5.593)$ \\
$\begin{array}{l}\text { Residency in Canada } \\
<5 y\end{array}$ & Reference & Reference \\
$6-9 y$ & 0.999 & 0.000 \\
$>10 y$ & 0.774 & $1.25(0.272-$ \\
& & $5.750)$ \\
Car ownership - Owned a & 0.977 & $0.986(0.371-$ \\
Vehicle & & $2.617)$ \\
\hline
\end{tabular}

Note: Coefficients in bold are statistically significant at $\alpha=0.05$.

Table 4.4 summarizes the results of the multivariate logistic regression analysis performed. The table list the $p$-value and $\operatorname{Exp}(B)$ and $95 \%$ C.I. range.

Table 4.5: Results of Multivariate Logistic Regression Analysis ( $n=69$ )

\begin{tabular}{|c|c|c|c|}
\hline $\begin{array}{l}\text { Dependent } \\
\text { Variable }\end{array}$ & Independent Variables & $p$-value & $\begin{array}{l}\text { Exp(B) with } 95 \% \\
\text { C.I. }\end{array}$ \\
\hline \multirow[t]{13}{*}{ Time of use } & RPKM & 0.687 & $\begin{array}{l}0.865(0.428- \\
1.751)\end{array}$ \\
\hline & Age & 0.437 & $\begin{array}{l}0.975(0.916- \\
1.038)\end{array}$ \\
\hline & Gender - Male & 0.177 & $\begin{array}{l}0.436(0.131- \\
1.457)\end{array}$ \\
\hline & Employment status - Full time & 0.356 & $\begin{array}{l}0.447(0.081- \\
2.473)\end{array}$ \\
\hline & Income & & \\
\hline & $<\$ 30,000$ & Reference & \\
\hline & $\$ 30,000$ to $\$ 45,000$ & 0.446 & $\begin{array}{l}0.445(0.056- \\
3.573)\end{array}$ \\
\hline & $\$ 45,000$ to $\$ 60,000$ & 0.145 & $\begin{array}{l}0.304(0.062- \\
1.504)\end{array}$ \\
\hline & $\$ 60,000$ to $\$ 75,000$ & 0.032 & $\begin{array}{l}0.122(0.018- \\
0.836)\end{array}$ \\
\hline & $>\$ 75,000$ & 0.775 & $\begin{array}{l}0.761(0.118- \\
4.897)\end{array}$ \\
\hline & $\begin{array}{l}\text { Residency in Canada } \\
<5 y\end{array}$ & Reference & \\
\hline & $6-9 y$ & 0.999 & 0.000 \\
\hline & $>10 y$ & 0.626 & $\begin{array}{l}1.571(0.255- \\
9.700)\end{array}$ \\
\hline
\end{tabular}




$\begin{array}{lll}\text { Car ownership - Owns a } & 0.779 & 0.577(0.170- \\ \text { Vehicle } & & 1.956)\end{array}$

Note: Coefficients in bold are statistically significant at $\alpha=0.05$.

According to the results of both bivariate linear regressions and multivariate linear regression, only gender produced a p-value of less than 0.05 which represents a statistically significant correlation. In other words, gender was the only variable that correlated/has a relationship with RPKM. Age, employment status, income, residency in Canada, and car ownership had a p-value higher than 0.05 , suggesting that no statistical relationship exist between these variables and RPKM.

The outcome of bivariate logistic regressions and multivariate logistic regression resulted in only income category $\$ 60,000$ to $\$ 75,000$ producing a $p$-value of less than 0.05 which represents a statistically significant correlation. This income category is the only variable that correlated/has a relationship with time of use. Age, employment status, other income categories, residency in Canada, and car ownership had a p-value significantly higher than 0.05 , suggestion no statistical significant correlation between these variables and time of use. 


\subsection{Discussion}

This section discusses the results of the study in relation to the hypotheses purposed at the beginning of this research paper. The latter part of the section outlines the implications of the study on policy and practice, as well as some of the limitations that might have affected the results of the study.

\subsection{Interpreting the results}

The results of the linear regression analyses and logistic regression analyses were interpreted in order to draw conclusions about the hypothesis and the study. First, the pvalue scrutinized to determine if there were any statistically significant correlations between the dependent and independent variables. For linear regression, the sign and value of the correlation were then noted, representing the direction of the correlation and strength of the correlation, respectively. For logistic regression, the value of $\operatorname{Exp}(B)$ was noted to signify the odds of an independent variable occurring compared to the reference independent variable for the reference dependent variable. Table 5.1 shows the interpretation of the linear regression analysis results. Table 5.2 shows the interpretation of logistic regression analysis results.

Table 5.1: Interpretation of linear regression results (Correlation between demographic variables and RPKM)

\begin{tabular}{lrr}
\hline Variable & \multicolumn{2}{c}{ Is there a correlation } \\
between the variables? & Direction of association \\
\hline Age & No & Negative \\
Gender & Yes & Positive \\
Employment status & No & Negative \\
Income & & Negative \\
$<\$ 30,000$ & No
\end{tabular}


$\$ 30,000$ to

$\$ 45,000$

$\$ 45,000$ to

$\$ 60,000$

$\$ 60,000$ to

$\$ 75,000$

$>\$ 75,000$

Residency in

Canada

$<5 y$

6-9y

$>10 \mathrm{y}$
No

No

No

No

No

No

No

No
Negative

Negative

Positive

Positive

Positive

Positive

Negative

Negative

Table 5.2: Interpretation of linear regression results (Correlation between demographic variables and time of use)

\begin{tabular}{|c|c|c|c|}
\hline Variable & $\begin{array}{l}\text { Is there a } \\
\text { correlation between } \\
\text { the variables? }\end{array}$ & $\begin{array}{l}\text { Is } \operatorname{Exp}(\mathrm{B}) \text { greater } \\
\text { or less than } 1 ?\end{array}$ & $\begin{array}{l}\text { Interpretation of } \\
\operatorname{Exp}(B)\end{array}$ \\
\hline Age & No & 1 & No correlation \\
\hline Gender & No & Less & No correlation \\
\hline $\begin{array}{l}\text { Employment status } \\
\text { Income }\end{array}$ & No & Less & No correlation \\
\hline$<\$ 30,000$ & No & - & - \\
\hline $\begin{array}{l}\$ 30,000 \text { to } \\
\$ 45,000\end{array}$ & No & Less & No correlation \\
\hline $\begin{array}{l}\$ 45,000 \text { to } \\
\$ 60,000\end{array}$ & No & Less & No correlation \\
\hline $\begin{array}{l}\$ 60,000 \text { to } \\
\$ 75,000\end{array}$ & Yes & Less & $\begin{array}{l}\text { Less likely to travel } \\
\text { during off-peak hours } \\
\text { (compared to } \\
<\$ 30,000)\end{array}$ \\
\hline $\begin{array}{l}>\$ 75,000 \\
\text { Residency in } \\
\text { Canada }\end{array}$ & No & 1 & No correlation \\
\hline$<5 y$ & No & - & - \\
\hline $6-9 y$ & No & 1 & No correlation \\
\hline$>10 y$ & No & Greater & No correlation \\
\hline Car Ownership & No & 1 & No correlation \\
\hline
\end{tabular}

The lack of correlation between the various demographic variables with RPKM and time of use suggests that the hypothesis of the study should be rejected. The hypothesis 
proposed that the flat fare pricing policy employed by the TTC creates inequity amongst different demographic groups of passengers. As well, based on a literature review, it was hypothesized that the current system might be benefiting those who are middle-aged, male, full-time workers, individuals from high-income households, non-immigrants, and own a vehicle (non-transit dependents), as they travel typically during peak hours and for long distances. In order to satisfy the hypothesis, a correlation must be drawn between RPKM/distance travelled and period of day when the system is used with various demographic variables such as age, gender, employment status, household income, residency in Canada, and vehicle ownership.

The results of the regression analysis on the data gathered revealed that a) only gender had a correlation with RPKM and b) only the income group $\$ 60,000$ to $\$ 75,000$ had a correlation with time of use. The coefficient between gender and RPKM was positive, indicating that males were more likely to pay more per kilometer travelled. Since an increase in the rate paid per kilometer travelled meant shorter distances travelled, males therefore were more likely to travel short distances. This conclusion is contrary to what has been observed in other cities. Males, as Cevero (1981), Cevero and Waches (1982), and Luhrsen \& Taylor (1997) have demonstrated in their studies, are part of the group that travelled longer distances and hence benefited from flat fares despite being generally more advantageous than females in society. The findings in this study indicates that the transit usage trends in Toronto may be different from other locations that have been studied and signify that local research should inform local transit policies.

Income group $\$ 60,000$ to $\$ 75,000$ had an $\operatorname{Exp}(b)$ of 0.026 from bivariate logistic regression and 0.032 from multivariate logistic regression. This indicates that income 
group $\$ 60,000$ to $\$ 75,000$ was less likely to travel during off-peak hours than the reference income group, $<\$ 30,000$. Although this may suggest that high income earners are more likely to travel during peak hours, there is little correlation between the income group $>\$ 75,000$ and time of travel, indicating that the relationship between high-income households and travel time (i.e. peak versus off-peak hours) is not entirely clear. None of the other variables display any relationship with RPKM or time of usage.

Without any real correlation between the various demographic variables with RPKM/distance travelled and time of usage, and the tenuous relationship between the correlated variables, it is unlikely that the flat fare pricing policy employed by the TTC creates inequity amongst various socio-demographic groups of passengers. In other words, it does not appear that one particular group (i.e. the "advantaged") are benefiting while others (i.e. the "disadvantaged") are being disfavoured by the flat fare pricing policy. This is not to say that inequity does not exist amongst general passengers. From the data gathered, it seems that a majority of passengers were likely being subsidized for their usage of the subway system based on distanced travelled. Assuming the actual cost to operate the subway is the average of the rate paid by those surveyed for every kilometer travelled- $\$ 0.365$ per kilometer (this number is likely higher due to TTC's need for government subsidizes to cover operating expenses) - a narrow majority of those surveyed were being subsidized for their use of the system. 49 out of 93 respondents (52.7\%) paid less than the average rate paid per kilometer travelled while 44 out of 93 respondents (47.3\%) paid more. In an entirely equitable system, all passengers would be paying the same amount per kilometer travelled on the subway. Since there were more respondents that were paying less than respondents paying more, and there was any 
discrepancy at all in the rate of pay per kilometer between passengers, the system did exhibit inequity between passengers.

This observation is also true for the time of day that a passenger uses the subway system. Respondents, on average, paid $\$ 0.11$ more per kilometer while travelling during peak hours compared to off-peak hours. Respondents who used the system during peak hours, therefore, were likely subsidizing respondents who used the system during offpeak hours. This is the opposite scenario to what the literature has suggested, but it is still an inequitbility between passengers as one group is subdizing another's use of the system.

Perhaps, it is interesting to note the type (i.e. direction) of the relationships between the various demographic variables with RPKM and time of use, despite the lack of a significant correlation between them due to a large standard error. Age and RPKM, for example, resulted in a negative coefficient. This indicates that older passengers paid lower rates per kilometer travelled and that they travelled longer distances. A negative coefficient resulted for employment status and RPKM, indicating that full time workers paid lower rates per kilometer travelled, and therefore, travelled longer distances. Similarly, car ownership and RPKM resulted in a negative coefficient, meaning those who owned a car were paying lower rates per kilometer travelled. The direction of association derived from the correlation between RPKM and the income categories indicate that individuals from lower income households paid lower rates per kilometer (travelled further) and high income households paid higher rates per kilometer (travelled shorter distances). Positive coefficients between less than 5 years residency in Canada meant immigrants were likely to have paid more per kilometer. 
The correlation between age and time of use resulted in an $\operatorname{Exp}(B)$ value of 0.975 . Since the value is close to one, however, it is likely that there is a minor relationship between the variables. The $\operatorname{Exp}(B)$ values derived from the correlation between gender and employment status were both less than one, denoting that females and part-time workers were more likely to travel during off-peak hours. Income groups $\$ 30,000$ to $\$ 45,000, \$ 45,000$ to $\$ 60,000$, and $\$ 60,000$ to $\$ 75,000$ all had $\operatorname{Exp}(B)$ values of less than 1, meaning that those who belong to these income groups were less likely to travel during off-peak hours compared to those in the $<\$ 30,000$ income group. There exists no correlation between income and time of use for income group $>\$ 75,000$, but it could be concluded that higher income individuals used the system during peak hours. There exist no correlation between 6-9 years residency in Canada and time of use, but for those who lived in Canada for more than 10 years were more likely to travel during off-peak hours when compared to those who have lived in Canada for 5 years or less. Immigrants, therefore, were more likely to travel during peak hours. There exist no correlation between car ownership and time of use and its $\operatorname{Exp}(B)$ was close to 1. Again, these relationships are merely interesting side notes to consider. Since these observations are highly unlikely to be statistically reliable due to large errors in calculation, they should not be used to establish any conclusions. 


\subsection{Implications for policy and practice}

Given that the conclusions drawn here are correct however, the TTC may consider changing the current flat fare pricing policy to a differentiated fare pricing policy. Such a change is unlikely to benefit disadvantaged groups and improve equity between passengers based on socio-demographic groups (as suggested by literature that it would). Yet, a majority of respondents were indeed being subsidized for their usage of the subway system based on distance travelled, indicating some geographic inequity between passengers. Only would a differentiated fare pricing policy that reflect the true cost of providing service allow for improvement of efficiency for the system and equity between passengers. Under such a policy, no users will be subjected to subsidizing or being subsidized for using the transit system as everyone are required to pay their fare share of the cost.

Because the inequity discovered is geographically based, the most appropriate fare pricing strategy to employ would be the zone-based or distance-based policies. Both strategies would satisfy the principle of "fair fares", where the longer the distance traveled within the system, the more one would pay (and vice versa). However, zone-based fares give rise to horizontal inequities by charging passengers a surcharge to cross through zones, even when traveling short trip (Cevero, 1990). Zone-based and distance-based pricing may also be problematic for some passengers, especially new and infrequent users of the transit system, to understand and use (Cevero, 1981), though the implementation of smart cards/electronic ticketing such as the Oyster card and Octopus card may help overcome the problem. It is also important for transit operators to consider the challenges and implications of changing a long standing fare pricing strategy and the 
impact on transit usage and collection infrastructure and policies. These considerations are out of the scope of this study, however. Nonetheless, they should be explored in future studies.

The suggestions provided above are mostly theoretical. While it remains a fact that flat fares are inequitable between passengers, whether the fare pricing policy should be time-based, distanced-based, or zone-based requires in-depth research focusing on not just factors in social equity, but efficiency as well. Overall, this study is an important first step in determining the most appropriate form of fare pricing for the TTC and moving towards a more efficient and equitable fare structure for other transit operators as well.

\section{$\underline{5.3 \text { Study Limitations }}$}

The study uses a number of assumptions which might have impacted the results. For example, the study focuses only on the distance travelled between subway station to subway station. This assumes that passengers surveyed used the subway system exclusively as their mode of travel. However, for some passengers, the subway was only a part of their trip; they also used the streetcar and/or bus system to reach their final destination. The distance travelled for these passengers would therefore be underestimated. It also assumes that every passenger paid $\$ 3$ for fares. However, in reality, some passengers could have used a monthly pass or presto card, meaning they paid less than $\$ 3$ for their trip (the actual amount that each passenger paid is hard to estimate as monthly passes depend on the number of trips taken during a month). These assumptions were made to simplify the data collection and analysis of the study. To overcome these limitations, the survey could include questions that ask respondents the 
modes of transportation they were taking on their trip and what fare product they used to pay for their trip. Taking these answers into consideration would allow for a more detailed analysis of the study.

There were also a number of methodical limitations that could have impacted the results of the study. The random selection of participants, while providing a general idea of who uses the system, where and when, makes for the potential for over- and underrepresentation of selected groups. This problem was particularly profound with age, where the sample population failed to represent the elderly (only 2 of the 93 surveyed were over the age of retirement while 48 out of 93 surveyed were under the age of 30 ), and with residency in Canada, where the sample population failed to represent immigrants/the recently landed (an overwhelming number of participants surveyed, 72 out of 93, have lived in Canada for 10 years or more). Underrepresentation can also been seen with gender, where there were considerably less men surveyed than woman, and with car ownership, where there were less participants with the ownership of a car than those without the ownership of car. Transit trends of underrepresented groups may not be accurately drawn. For example, the data gathered from the two elderly participants were used in the analysis and were assumed to be an accurate depiction of the trip patterns of the elderly demographic group. However, it is very unlikely that this true; more elderly participants would be required to confirm the validity of these assumption. This problem may be unavoidable, however, as everyone's trip and demographic information can vary greatly. If an older population, for example, was selected to be surveyed, the resulting data might skew a variable into one direction or another, creating the problem of misrepresentation for said variable. 
The scale of the study is a limitation as well. The time period and number of stations within which the surveys were conducted, as well as the total sample size of the survey were restricted due to time and resources constraints. More surveys conducted at different times of the day (e.g. mornings and nights), at different stations/areas of the city (i.e. Etobicoke, Scarborough, not just the downtown core, but especially in priority neighbourhoods that have a higher concentration of low income populations), and on different forms of transit systems (i.e. not just limited to subways, but on streetcars and buses a well) would allow for a better representation of the population. A larger, more encompassing study might provide entirely different results (for example, ones that show a correlation between certain demographic variables with distance and/or time of usage) but also ensure more accurate results. 


\section{$\underline{6.0 \text { Conclusions }}$}

This project uses quantitative surveys and statistical analyses to examine fare equity amongst socio-demographic groups of passengers who use Toronto's subway system, using quantitative surveys and statistical analysis.

Trip and demographic characteristic data were gathered from randomly selected subway passengers through a number of intercept surveys. To draw a relationship between demographics groups and travel behaviour, data (i.e. RPKM and time of usage) were correlated with demographic characteristics (i.e. age, gender, employment status, income, residence in Canada, and car ownership) using linear bivariate regression, linear multivariate regression, bivariate logistic regression and multivariate logistic regression. It was found that there were no statistically significant correlation between RPKM and age, employment status, income, residency in Canada, and car ownership. Similarly, no statistically significant correlation exist between time of usage and age, gender, employment status, income (except for income group $\$ 60,000$ to $\$ 75,000$ ), and car ownership. Relationship did exist between RPKM and gender and time of use and income group $\$ 60,000$ to $\$ 75,000$.

The lack of correlation between the various demographic variables with RPKM and time of use suggest that the flat fare pricing policy employed by the TTC does not create inequity amongst different socio-demographic groups of passengers. No evidence suggest that middle-aged, males, full-time workers, individuals from high-income households, non-immigrant, and those who own a vehicle (non-transit dependents) are those who travel on peak hours and for long distances (and vice versa). As such the 
pricing policy used by the TTC does not benefit or disfavour a particular group over the other. This is not to suggest that there are no inefficiency or inequality resulting from flat fares. Indeed, it was found that passengers that use the system during off-peak hours and/or for short trips were subsidizing passengers that use the system during long-peak hours and/or for long trips.

This study is by no means comprehensive. A number of limitation could have affected the accuracy of the results and conclusions drawn from them. Further research topics could involve hypothesising the possible discrepancies between what the literature suggested and the conclusions that were drawn here. Another research topic could test the conclusions drawn here by conducting a more extensive, comprehensive study of the entire TTC system. Overall, this study is an important first step in determining the most appropriate form of fare pricing for the TTC to make the system as efficient and equitable as possible. 


\section{Appendix A}

\section{Study: Impacts of subway pricing on fare equality among passengers: A Toronto case study}

Questionnaire

Date:

Location of survey:

Survey Code:

Trip Information

For the following questions, please answer based on your most recent trip.

1. Was the trip/will the trip be a work trip or non-work trip: Work trip Non-work trip

2. a) Which city did you begin your trip?

b) Which city did you/will you begin your trip?

3. a) Which subway station was your origin station?

b) Which subway station was your destination station?

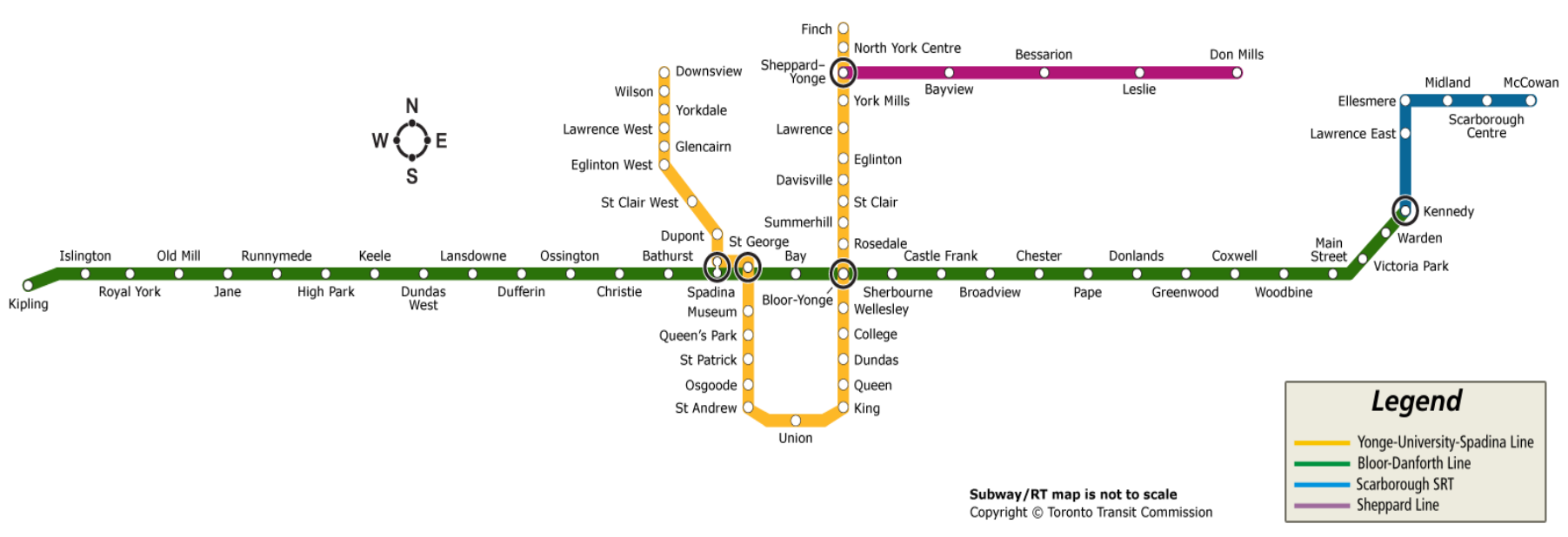

4. Is this your typical route of travel? Yes No

5. When do you typically use the subway system?

$\begin{array}{llllllll}\text { Pre- } & \text { Morning } & \text { Mid- } & \text { Lunch } & \text { Mid-day } & \begin{array}{l}\text { Evening rush } \\ \text { Night }\end{array} & \begin{array}{l}\text { Late night } \\ \text { (7:00pm to }\end{array} \\ \text { morning } & \text { rush } & \text { morning } & (11: 00 \mathrm{pm} \text { to } \\ \text { rush } & (7: 30 \mathrm{am}- & (9: 30 \mathrm{am} \text { to } & 1: 00 \mathrm{pm}) & 4: 00 \mathrm{pm}) & 7: 00 \mathrm{pm}) & 10: 00 \mathrm{pm}) & 1: 00 \mathrm{am}) \\ (6: 00 \mathrm{am}- & 9: 30 \mathrm{am}) & 11: 00 \mathrm{am}) & & & & & \\ \text { 7:30am) } & & & & & & \end{array}$

\section{Demographic Information:}

6. What is your age? :

7. Are you a:

Male

or

Female

8. What is your occupation:

Full time or Part time?

$\begin{array}{lllllll}\text { 9. What is your } & \text { Less than } & \$ 15,000 \text { to } & \$ 30,000 \text { to } & \$ 45,000 \text { to } & \$ 60,000 \text { to } & \text { More than } \\ \text { household Income: } & \$ 15,000 & \$ 29,999 & \$ 45,000 & \$ 60,000 & \$ 75,000 & \$ 75,000\end{array}$


10. On average, how much do you spend a month on transit?

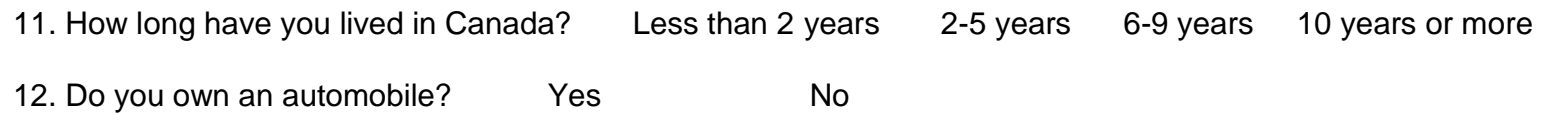




\section{$\underline{\text { References }}$}

Altshuler, A. (1979). The Urban Transportation System: Politics and Policy Innovation. Cambridge: MIT Press

Axisa, J.J., Scott, D.M., \& Newbold, B. (2011). Factors influencing commute distance: a case study of Toronto's commuter shed. Journal of Transport Geography, 24 (2), 123-129.

Banister, D. \& Hall, P. (1981). Transport and public policy planning. London: Mansell.

Bay Area Rapid Transit (n.d.) Fare Calculator. Retrieved from: http://www.bart.gov/tickets/calculator

Bucciarelli, E., Pagliari, C., Muratore, F., Odoardi, I. (2012). A comparative analysis of literacy rate in contributing to social exclusion insights, G. Parodi \& D. Sciulli (ed.), Social Exclusion - Short and Long Term Causes and Consequences (pp. 35-66). Physcia-Verlag HD

Berlin Verkehrsbetriebe (n.d.), Tickets \& Fares. Retrieved from: http://www.bvg.de/index.php/en/17102/name/Tickets+\%2B+Fares.html

Bradshaw, J., Kemp, P.A., Baldwin, S., \& Rowe, A. (2004). The Drivers of Social Exclusion. London: Social Exclusion Unit

Calgary Transit (2011). City of Calgary, Calgary Transit. Calgary Transit Funding and Fare Strategy. Retrieved from: http://www.calgarytransit.com/pdf/Fare-Strategy-Report-June-2011.pdf

CanMap RouteLogistics 2010.3 (CMA Toronto Clip) [Shapefile]. DMTI Spatial Inc., 2010. Available: Ryerson University Library Controlled Access.

Cevero, R. (1981). Flat versus differentiated transit pricing: what's a fair fare? Transportation, 10, 211 - 232.

Cevero, R. \& Wachs, M. (1982). An Answer to the transit crisis: the case for distance based fares. Journal of Contemporary studies, 59-70.

Cevero, R. (1990). Transit pricing research: a review and synthesis. Transportation, 17, 117-139.

Chatterjee, S., Hadi, A. S., \& Price, B. (2000). Regression analysis by example. (3rd ed.). New York City: John Wiley \& Sons, Inc.

City of Burlington. City of Burlington, Transit Department (2013). Transit Fare Strategy. Retrieved from website: http://cms.burlington.ca/AssetFactory.aspx?did=29547

City of Hamilton (n.d.). Support Programs - Afford Transit Pass Program. Retrieved from: http://www.hamilton.ca/HealthandSocialServices/SocialServices/SupportPrograms/AffordableTransitPass.htm

City of Guelph (2014). Affordable bus pass. Retrieved from: http://guelph.ca/living/getting-around/bus/fares-andpasses/affordable-bus-pass/

City of Regina (n.d.) Discounted monthly pass program. Retrieved from: http://www.regina.ca/residents/transitservices/regina-transit/choose-your-fare/discounted-monthly-pass/

Chicago Transit Authority (n.d.). CTA Fares \& Tickets. Retrieved from: http://www.transitchicago.com/fares/ 
Church, A., Frost, M. \& Sullivan, K. (2000). Transport and Social Exclusion in London. Transport Policy 7, 195-205.

Clifton, K. \& Lucas, K. (2004). Examining the empirical evidence of transport inequality in the US and UK, K. Lucas (ed.), Running on empty: transport, social exclusion an environmental justice (pp. 15-37). Bristol: The Policy Press.

Commission of the European Communities (CEC) (1993). Towards a europe of solidarity: intensifying the fight against social exclusion, fostering integration. Brussels.

Crowther, A. (2011) Assessing equity in transit pricing: an analysis of Triangle Transit (Masters project) Duke University. Retrieved from: http://dukespace.lib.duke.edu/dspace/handle/10161/3586

Currie, G. \& Delbosc, A. (2011). Transport disadvantage: a review, G. Currie (ed.), New Perspectives and Methods in Transport and Social Exclusion Research (pp. 15-25). Bingley: Emerald

Department for International Development, (2005). Reducing poverty by tackling social exclusion: A DFID policy paper. Retrieved from Department for International Development website:

http://www2.ohchr.org/english/issues/development/docs/socialexclusion.pdf

Doxsey, L.B. \& Spear, B.D. (1981). Free-fare transit: some empirical findings. Transportation Research Record, 799, 47-49.

Erba, S. (2005). Equity issues and public transport fares: broad-brush theoretical analysis (Policy paper). Polytechnic University of Milan/University of Leeds.

Edmonton Transit System (2011). City of Edmonton, Edmonton Transit System. The way we move using public transit. Retrieved from: http://www.edmonton.ca/transportation/transit/ETS_BusPlan_2011-2013_v6b.pdf

Giuliano, G. (2005). Low income, public transit, and mobility. Transportation Research Record: Journal of the Transportation Research Board, 1927(1), 63-70.

Grand River Transit (n.d.). Reduced Income Rider Programs. Retrieved from: http://www.grt.ca/en/riderprograms/reducedincome.asp

Grengs, J. (2001) Does public transit counteract the segregation of carless households? Transportation Research Record 1753, 3-10.

Harrison, A.J., Douglas, A. (1974). The distribution of benefits resulting from different fares policy, in TRRL Symposium on public transport fare structure: papers and discussion: the proceedings of a Symposium held at the Transport Road Research Laboratory, Crowthorne

Hooper, P. (n.d). What is a P-value? Retrieved from:

http://www.stat.ualberta.ca/ hooper/teaching/misc/Pvalue.pdf

Kain, J.F. (1968). Housing Segregation, Negro Employment and Metropolitan Decentralization. The Quarterly Journal of Economics, 82 (2), 175 - 197.

Katenka, N. (2012). Lecture 5.3. (Lecture, Boston University)Retrieved from http://math.bu.edu/people/nkatenka/MA116/Week5Lecture3.pdf 
King County Metro (2011). Fares \& ORCA. Retrieved from: http://metro.kingcounty.gov/fares/

Kitchen, H. \& Lindsey R. (2013). Financing Roads and Public Transit in the Greater Toronto and Hamilton Area (Independent Study). Residential and Civil Construction Alliance of Ontario.

Koski, R. W. (1992). Bus Transit, G.E. Gray and L. A. Hoel (ed.), Public Transportation (PP. 148-176). Englewood Cliffs:Prentice-Hall.

Levitas, R. (2005). The inclusive society and New Labour. Basingstoke: Palgrave Macmillan.

Lin, K., Xu, Y, Huang T., Zhang, J. (2012). Social exclusion and its causes in east Asian societies: evidences from SQSQ survey data. Social Indicators Research, 112, 641-660.

Lucas, K. (2004a). Transportation and Social Exclusion: A survey of the Group of Seven nations. FIA Foundation.

Lucas, K. (2004b). Running on empty: transport, social exclusion an environmental justice. Bristol: The Policy Press.

Lucas, K. (2012). Transport and social exclusion: where are we now?. Transport Policy, 20, 105-113.

Luhrsen, K. F., \& Taylor, B. D. (1997). The high cost of flat fares: an examination of ridership demographics and fare policy at the los angeles MTA (Working Paper). Los Angeles, California: UCLA Institute of Transportation Studies

MacKinnon, S. (2008). Poverty and social exclusion solving complex issues through comprehensive approaches. Publication, Canadian Centre for Policy Alternatives. Retrieved from http://www.policyalternatives.ca/sites/default/files/uploads/publications/Manitoba_Pubs/2008/Poverty_ and_Social_Exclusion.pdf

Mass Transit Railway (n.d.) Train Services. Retrieved from: http://www.mtr.com.hk/eng/fares_tickets/train_service_index.html

Mathieson, J., Popay, J., Enoch, E., Escorel, S., Hernandez, M., Johnston, H., Rispel, L. World Health Organization, (2008). Social exclusion meaning, measurement and experience and links to health inequalities a review of literature. Retrieved from World Health Organization website:

http://www.who.int/social_determinants/media/sekn_meaning_measurement_experience_2008.pdf.pdf

McLaughlin, J., and Boyle, D. K. (1997) Transit incentive programs for transit-dependent riders. Transportation Research Record 1604, 139-145.

Metropolitan Transportation System (n.d.). Fares \& MetroCard. Retrieved from: http://web.mta.info/metrocard/mcgtreng.htm

Meyer, J. R. (1965). The Urban Transportation Problem. Cambridge, MA: Harvard University Press.

Morgan, T. (1992). Strategies to overcome transport disadvantage. Canberra: Department of the Prime Minister and Cabinet

Perrin, C. (1982). Implications of social and spatial trends for transit operations and research. Transportation Research Record, 877, 97-103. 
Pucher, J. \& Renne, J.L. (2003). Socioeconomies of Urban Travel: Evidence from the 2001 NHTS. Transportation Quarterly, 57, 3, 49-77.

Rock, S. (1975). The redistributive effects of mass transit in the Chicago area (Ph.D. dissertation). Northwestern University

Room, G. Directorate General V, Employment, Social Affairs, and Industrial Relations, Commission for European Communities (1992). Observatory on national policies to combat social exclusion. Brussels.

Taipei Metro (n.d.). Fare \& travel time inquiries. Retrieved from: http://english.trtc.com.tw/ct.asp?xItem=1056377\&CtNode $=49782 \& \mathrm{mp}=122032$

Taylor, B.D., Garrett, M., \& Iseki, H. (2000). Measuring Cost Variability in Provision of Transit Service. Transportation Research Record: Journal of the Transportation Research Board, 1735, 101-112.

Toronto Transit Commission (n.d.). Prices. Retrieved from: http://www.ttc.ca/Fares_and_passes/Prices/

Toronto Transit Commission. Toronto Transit Commission (2013). Five-Year Corporate Plan. Retrieved from Toronto Transit Commission website: http://www.ttc.ca/PDF/TTC_Corporate-Plan_accessible_v2.pdf

Toronto Transit Commission (2014). 2014 Fare Schedule. Retrieved from: http://www.ttc.ca/Fares_and_passes/Prices/

Tokyo Metro (n.d.). Tokyo Metro Transfer Planner \& Fare Calculation. Retrieved from: http://www.tokyometro.jp/en/ticket/search/

TransLink (n.d.). Fare Zone Map. Retrieved from: http://www.translink.ca/en/Fares-and-Passes/Fare-ZoneMap.aspx

Transport for London (n.d.). Tickets > Fares. Retrieved from: http://www.tfl.gov.uk/tickets/fares-2014/29089.aspx

Transportation Research Board, Federal Transit Administration, (2003). Fare policies, structures and technologies: Update. Retrieved from Transportation Research Board website:

http://onlinepubs.trb.org/onlinepubs/tcrp/tcrp_rpt_94.pdf

Seguin, G. (n.d.). Provincial and territorial anti-poverty strategies and poverty reduction campaigns. Retrieved from http://www.canadiansocialresearch.net/antipoverty.htm

Silver, H. (1995). Reconceptualising social disadvantage: Three paradigms of social exclusion, G. Rodgers, C. Gore and J.B. Figueiredo (eds.), Social exclusion: rhetoric, reality, responses, International Labour Organisation, Geneva.

Social Exclusion Unit (1997). Social Exclusion Unit: Purpose, Work Priorities and Working Methods. London: HMSO.

Social Exclusion Unit, Office of the Deputy Prime Minister (2003). Making the connections: Final report on transport and social exclusion. Retrieved from Social Exclusion Unit website: http://assets.dft.gov.uk/statistics/series/accessibility/making-the-connections.pdf

Stanley, J.R. (2011). Social exclusion, G. Currie (ed.), New Perspectives and Methods in Transport and Social Exclusion Research (pp. 15-25). Bingley: Emerald 
Stantec Consulting. Canadian Urban Transit Association (2011). National strategies on public transit policy framework. Retrieved from website: http://www.cutaactu.ca/en/publictransit/publicaffairs/resources/FianIReport-G8.pdf

StatsDirect (n.d.). P values. Retrieved from: http://www.statsdirect.com/help/default.htm\#basics/p values.htm

Spurr, B. (2013, Oct. 18). TTC nixes lower fares for the poor, seniors. Now Toronto. Retrieved from http://www.nowtoronto.com/news/story.cfm?content=194886

Vickrey, W. (1973). Current issues in transportation in N. Chamberlain (ed.). Contemporary Economic Issues. Homewood, IL: Irwin.

Visit Copenhagen (n.d.). Tickets \& prices. Retrieved from: http://www.visitcopenhagen.com/copenhagen/service/tickets-and-prices

Wachs, M. \& Kumagai, G.T. (1973). Physical accessibility and a social indicator. Socio-Economic Planning Science, 7(5), 437-456

Wixey, S., Jones, P., Lucas, K. \& Alridge, M. (2005). Measuring accessibility as experienced by different socially disadvantaged groups. London, Transit Studies Group, University of Westminster.

Wuensch, K.L. (2014). Binary Logistic Regression with SPSS. Retried from: http://core.ecu.edu/psyc/wuenschk/MV/Multreg/Logistic-SPSS.PDF 